\title{
INSCRIPTIONS ARABES ET PERSANES SUR LES ARMES MUSULMANES DE LA TOUR DE LONDRES
}

\author{
PAR \\ LUDVIK KALUS
}

LORS d'une récente visite à Londres, Mr. A. V. B. Norman, Master of the Armouries à la Tour de Londres, m'a proposé d'étudier les inscriptions arabes et persanes sur les armes musulmanes exposées dans une nouvelle salle, ouverte au public au printemps $1978^{1}$. Jusqu'à présent, très peu d'inscriptions se trouvant sur les objets de cette importante collection ont été étudiées et, à ma connaissance, aucune des inscriptions n'a été publiée. Le temps límité de mon séjour à Londres et les conditions peu favorables pour une étude approfondie dans une salle toujours fréquentée par un grand nombre de visiteurs ne m'ont pas permis d'entreprendre l'étude des objets eux mêmes, avec l'analyse des éléments morphologiques et décoratifs des armes. Ainsi mes recherches se sont limitées au déchiffrement des inscriptions soit sur place, soit plus tard à mon retour à Paris, d'après les photographies prises dans le musée.

L'étude présentée ici se veut être le résultat d'une prospection épigraphique dans la collection des armes musulmanes de la Tour de Londres sous forme d'un inventaire des inscriptions arabes et persanes sur les armes de cette collection ${ }^{2}$. Cet inventaire ne tient donc pas compte des éléments morphologiques et décoratifs dont l'étude devrait faire partie d'une analyse descriptive complète. Cette étude sera effectuée par le

1 Je tiens à exprimcr à Mr. A. V. B. Norman, Master of the Armouries, mes vifs remerciements pour son aimable proposition, pour toutes les facilités qu'il m'a accordées pendant mon travail à la Tour de Londres et pour son autorisation de publier les inscriptions et leurs reproductions. Mes remerciements vont également à Mr. N. Hall, Research Assistant, qui m'a accompagné pendant mon séjour à la Tour de Londres, me sortait les objets des vitrines et attendait patiemment, souvent de longs moments, la prise d'une photo ou le déchiffrement.

2 Cet article est préparé conformément au programme de recherche de I'U.R.A. no. 22 du C. N. R. S., dans le cadre du Centre d'Epigraphie Arabe de la IVème section de l'E.P.H.E. à Paris. Une étude analogue a été entreprise par le présent auteur à la Wallace Collection de Londres, également grâce à l'aimable autorisation de Mr. A. V. B. Norman, sa rédaction est en cours et elle sera publiée prochaînement. 
personnel du musée lui-même et l'inventaire des inscriptions présenté ici n'est qu'une étape préliminaire pour ce travail final souhaité.

Les armes musulmanes à inscriptions que j'ai pu voir sont au nombre de trente neuf. La plupart d'entre elles sont actuellement exposées dans la nouvelle salle du Moyen Orient, quelques unes se trouvent dans les réserves du musée. D'une façon générale, on peut les dater entre le XVème et le début du XXème siècle et, géographiquement, elles couvrent l'aire entre le Maroc et l'Inde, c'est-à-dire pratiquement tout le monde musulman traditionnel de la période concernée. Les datations et les attributions à une région donnée ont été reprises d'après les indications du musée et certaines d'entre elles seront à modifier lors de la description raisonnée, dans laquelle les données épigraphiques vont constituer un élément important. Pour les attributions où il est déjà évident d'après le caractère des inscriptions qu'elles sont erronées, je mentionne «date» ou «région à déterminer».

Ce répertoire est classé par groupes définis par le type d'armes. A l'intérieur de chaque groupe, les objets sont classés chronologiquement par siècles, les armes datées étant rares. La description se limite à une définition générique, les détails ne sont donnés que pour situer et pour décrire l'inscription. Le commentaire est le plus succint possible, comme c'est l'habitude dans un inventaire.

Les photographies accompagnant le texte représentent un choix d'inscriptions intéressantes par leur graphie ou par leur côté décoratif, d'inscriptions non banales ou bien d'inscriptions ou de parties d'inscriptions posant des problèmes. Toutes les photographies ont été prises par l'auteur de ces lignes et, pour respecter le souhait du Directeur de l'Armurerie, elles ne représentent jamais un objet entier.

Dans la présentation des inscriptions, les points de suspension désignent des parties non lues, tandis que les groupes de «x» désignent les parties effacées.

\section{N V ENT A I R E}

\section{ARMURES}

a) Boucliers

\section{No. 1 Bouclier circulaire en acier}

Région à déterminer, XVème ou début du XVI siècle

No. d'inv. 26/127 A; provient de l'Arsenal de Ste. Irène à Istanbul 


\section{Autour de l'umbo}

Dans un bandeau circulaire, quatre cartouches; écriture cursive; caractères délimités sur la surface par les contours gravés; le fond entre les caractères est argenté.

$$
\begin{aligned}
& \text { ublut (1) }
\end{aligned}
$$

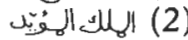

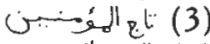

$$
\begin{aligned}
& \text { (4) الوغ اليك }
\end{aligned}
$$
(1) Le sultan
(2) roi assisté [de Dieu]
(3) couronne des croyants
(4) Ulug Beg... (Fig. 1)

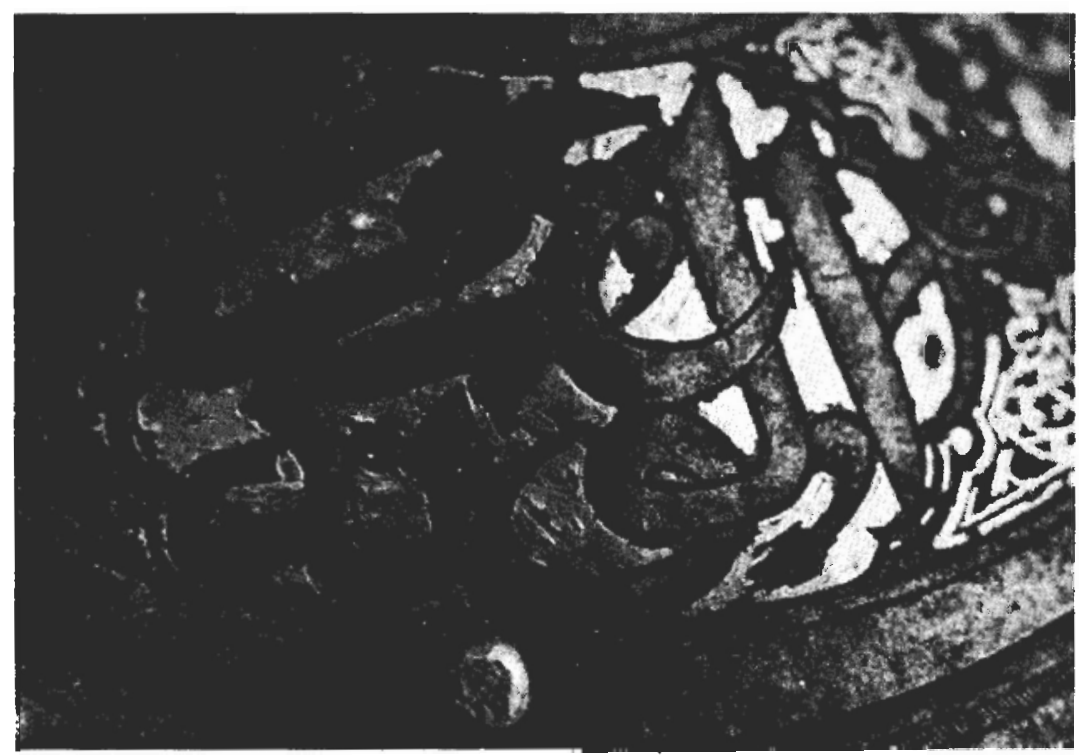

FIG. 1 
II. Sur les flancs, autour de l'umbo

Dans quatre cartouches; écriture cursive; caractères argentés, délimités sur la surface par les contours gravés.

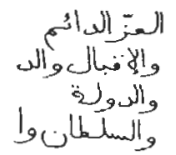

(1) Puissance éternelle

(2) bonne fortune, pou[voir]

(3) pouvoir

(4) force

III. Dans la bordure circulaire du bouclier

Dans onze cartouches allongés aux côtés latéraux trilobés, reliés par un entrelacs; écriture cursive; caractères argentés, délimités sur la surface par les contours gravés.

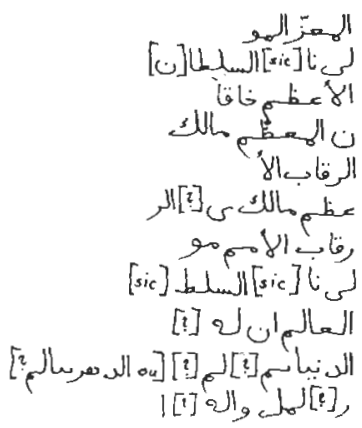

(1) Celui qui donne la force, maî[tre ]

(2) notre [maî]tre, le sulta[n]

(3) très grand, hāqā $[n]$

(4) [hăq̄ā $] \mathrm{n}$ auguste, souverain

(5) des nuques, très

(6) grand, souverain des nu[ques]

(7) [des nu]ques des nations, maî[tre] .

(8) notre [maî]tre, sulta[ $n]$

(9) savant...... (?) (Fig. 2a)

(10) monde...... (?) [ou temps...? ] (Fig. 2b)

(11) (?) (Fig. 2c) 


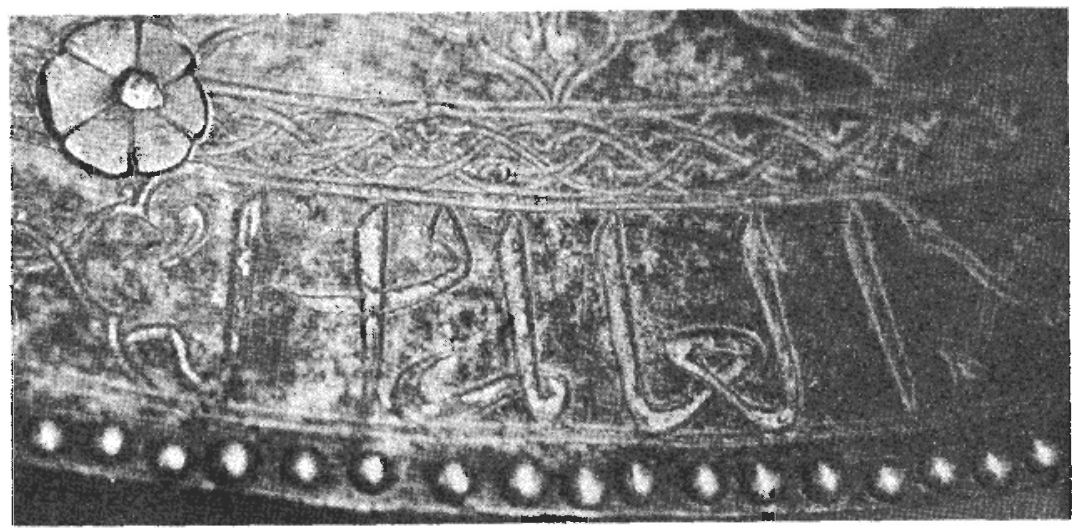

FIG. 2a

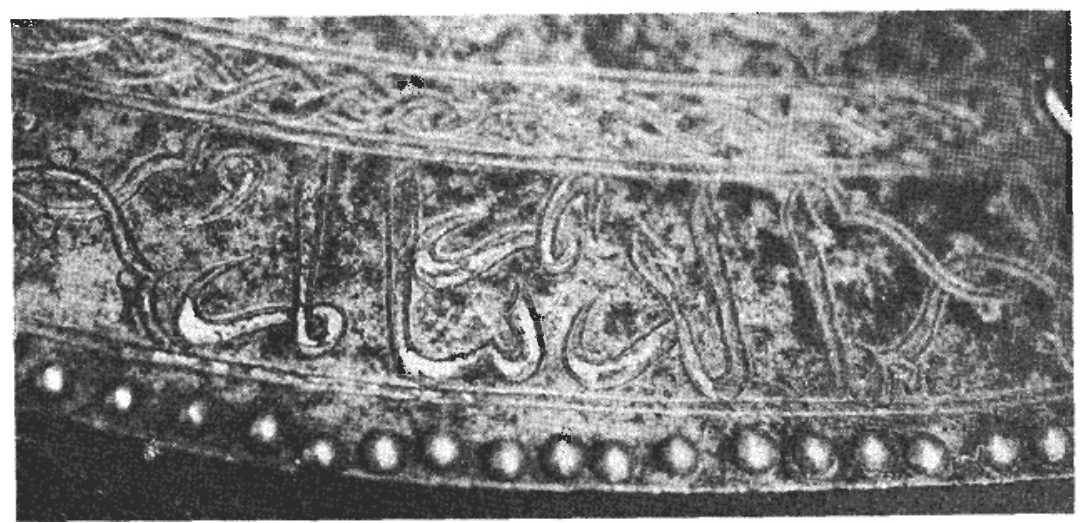

FIG. 2b

On constate qu'il y a une certaine différence entre les inscriptions sur l'umbo d'une part et les inscriptions sur les flancs et dans la bordure du bouclier d'autre part. Les dernières sont exécutées en caractères beaucoup moins épais que les premières et leur surface est argentée, ce qui n'est pas le cas des inscriptions sur l'umbo, où c'est le fond entre les caractères qui est argenté. Tandis que les inscriptions sur les flancs 


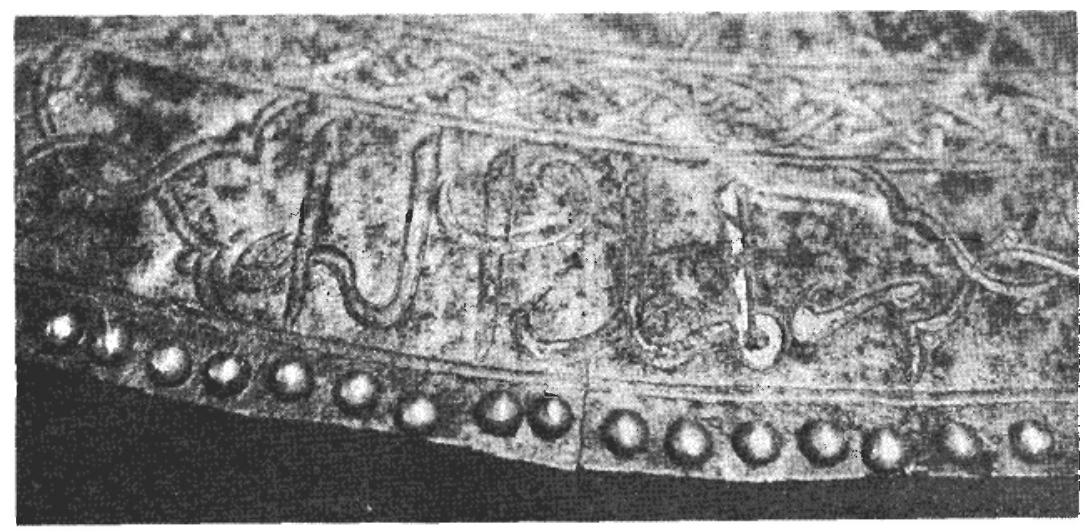

FIG. 2c

contiennent des formules «banales» exprimant des voeux (II) et les inscriptions dans la bordure la titulature d'un souverain inconnu, avec beaucoup d'erreurs et d'imprécisions (III), l'inscription sur l'umbo (I) a l'air d'être correcte et mentionne même un certain Ulug Beg, dont le nom est suivi d'un mot non lu. Remarquons le titre tāğ al-mu'minin qui précède le nom, qui est loin d'être courant et nous ne l'avons pas trouvé ailleurs ${ }^{3}$. S'agit-il du Timouride Ulug Beg b. Abi Sa ${ }^{a} \mathrm{id}(†$ 853)? Ceci nous paraît peu probable car il n'a jamais été, à notre connaissance, attesté avec le titre mentionné. Faut-il chercher ce nom parmi les nombreux Mamelouks en Syrie et en Egypte? Nous ne l'avons pas trouvé dans Les biograpbies du Manbal Safi ${ }^{4}$ et pour l'instant nous sommes obligé de le laisser non identifié. Notons encore que la graphie habituelle du nom Ulug est $\dot{\tau}^{\prime l}$ et non الرغ, comme c'est le cas sur le bouclier en question. Parmi les titres dans la bordure, on remarque le titre băgān, qui est d'origine persane et qui était «porté par divers souverains mongols de Perse, de Mésopotamie et d'Asie-Mineure» ${ }^{5}$. En Egypte, le premier souverain mamelouk qui le porte est le sultan Qāytbāy (872901/1468-1496) et ce titre est suivi de l'adjectif al-mu'azzam ${ }^{6}$, comme sur le bouclier. Il a été employé également à l'époque ottomane. Le ti-

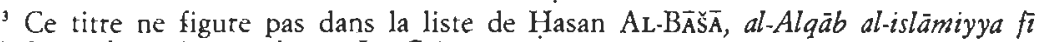
l-ta'rīb wa l-w'atä'iq wa l-ätär, Le Caire, 1957.

“Les biographies du Manbal Safi, trad, résumée par G. WIET, Le Caire, 1932.

'CIA I. Egypte, 1. p. 496.

- CIA I, Egyptc, 1, p. 496; AL-BĀšs̆, op. cit., p. 272. 
tre mälik ruqàb al-umam a été enregistré pour la première fois à l'époque gaznawide ${ }^{7}$ et a connu un emploi courant à partir de l'époque mongole en Iran ainsi q'u'en Syrie et en Egypte à l'époque mamelouke. Les titres sur ce bouclier sont à rapprocher des titres des inscriptions du casque no. 5 .

L'examen épigraphique suggère une comparaison attentive entre l'umbo et le reste de la base du bouclier car il se peut que les deux parties proviennent d'ateliers différents.

No. 2 Bouclier circulaire en acier

Iran, XIXème siècle

Château de Windsor -prêté par Sa Majesté la Reine

Dans la bordure, aux deux extrémités opposées.

Deux cartouches allongés aux côtés latéraux polylobés; deux lignes dans chaque cartouche; écriture cursive; caractères damasquinés d'or.

$$
\begin{aligned}
& \text { A (1) - A }
\end{aligned}
$$

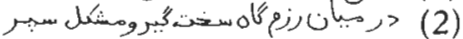

$$
\begin{aligned}
& \text { 3 (1) - B }
\end{aligned}
$$

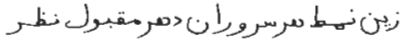

A - (1) Digne de la main du rois des rois puissant

(2) Celui qui au milieu de la bataille tient ferme et est bien défendu (par le bouclier) (Fig. 3a)

$\mathrm{B}$ - (1) Je t'ai dit: «Ce dessin est la marque de l'ornement des grands rois

(2) En cette compagnie tous les seigneurs du temps sont agréables à voir» (Fig. 3b)

Quatrain persan louant le bouclier et son porteur.

No. 3 Bouclier circulaire en acier

Iran (?), XIXème siècle

No. d'inv. 26/132 A

Dans la bordure.

${ }^{7}$ AL-BĀ̄ $\overline{\mathrm{A}}$, op. cit., p. 446. 


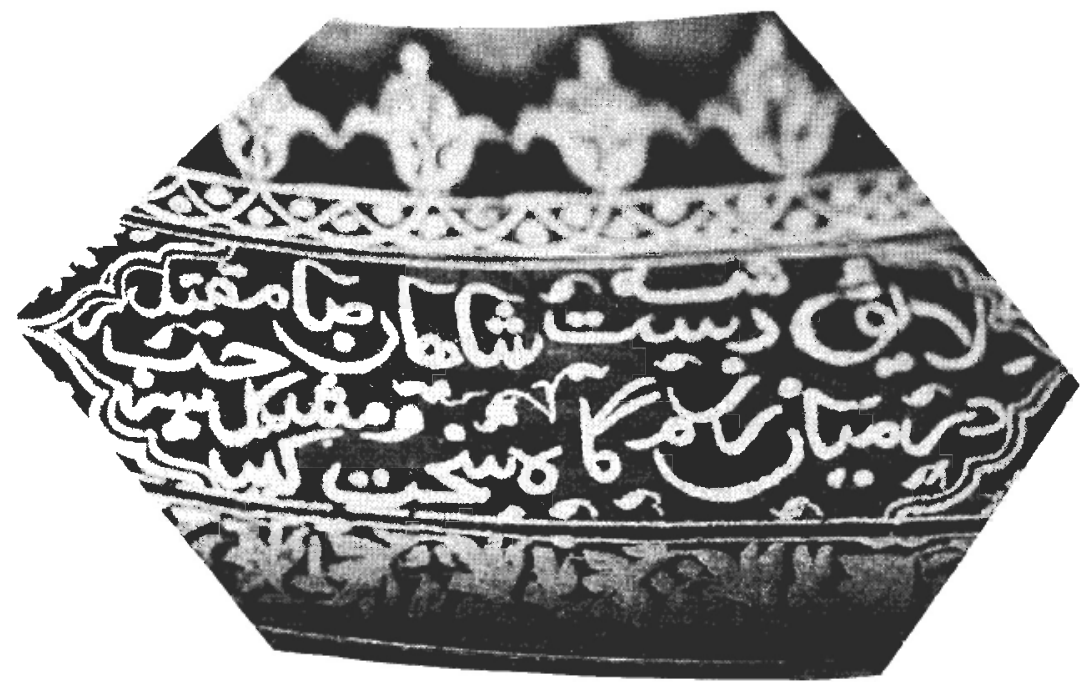

FIG. 3a

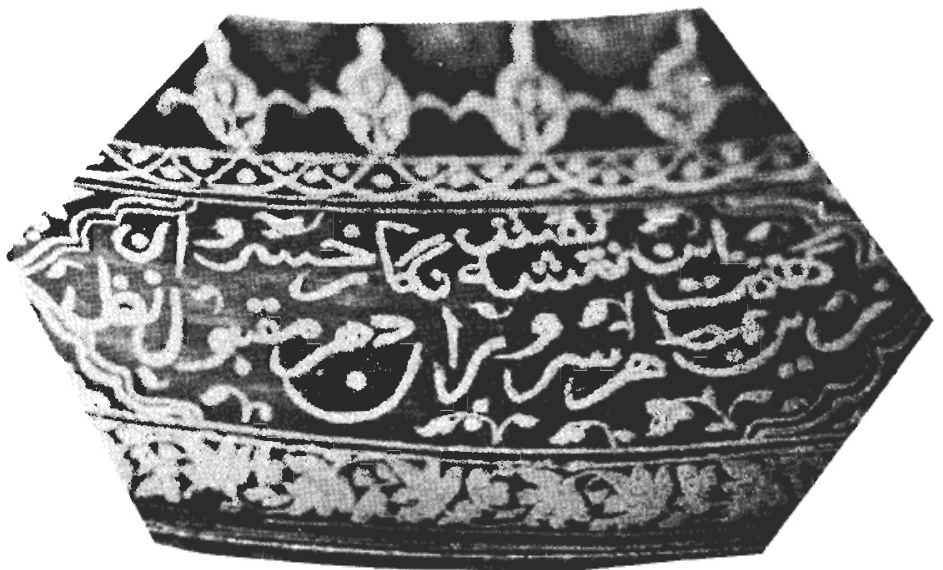

Fig. 3b 
Huit cartouches ovales allongés alternant avec huit cartouches circulaires; écriture cursive; caractères en relief, damasquinés d'argent.

L'inscription peut être considérée comme une pseudo-inscription imitant des inscriptions contenant des vers persans. Ce type d'inscriptions est courant au XIXème siècle et il se peut qu'en comparant un certain nombre de ces inscriptions entre elles, il serait possible de reconstituer l'archétype ou des archétypes, dont elles sont éloignées d'une façon méconnaissable à première vue.

\section{No. 4 Bouclier circulaire en acier}

Iran, XIXème siècle

No. d'inv. 26/130 A

\section{Sur l'umbo}

Médaillon circulaire; trois lignes en écriture cursive ( $\operatorname{ta}$ 'līq); caractères en relief, ciselés et dorés.

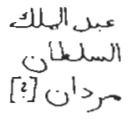
(1) 'Abd al-Malik (Fig. 4)
(2) sultan
(3) Guerriers du (?)

II. Dans la bordure

Huit cartouches polylobés alternant avec huit cartouches à décor figuratif; écriture cursive (ta līq); caractères en relief, ciselés et dorés (Fig. 5a-h).

L'inscription, qui est en persan, n'a pas été déchiffrée et la question se pose, si elle est exécutée correctement. Nous avons pensé aux vers du Săbnäme, car on peut y voir le nom de Rustam à côté du nom de son cheval appelé Ruhš, si la lecture de ces deux noms est correcte (Fig. 5h). Mais nos recherches d'après le glossaire du Sābnāme de Fritz Wolff ${ }^{8}$ n'ont apporté aucun résultat.

- Fritz Wolff, Glossar zu Firdosis Scbahname, Berlin, 1935. 


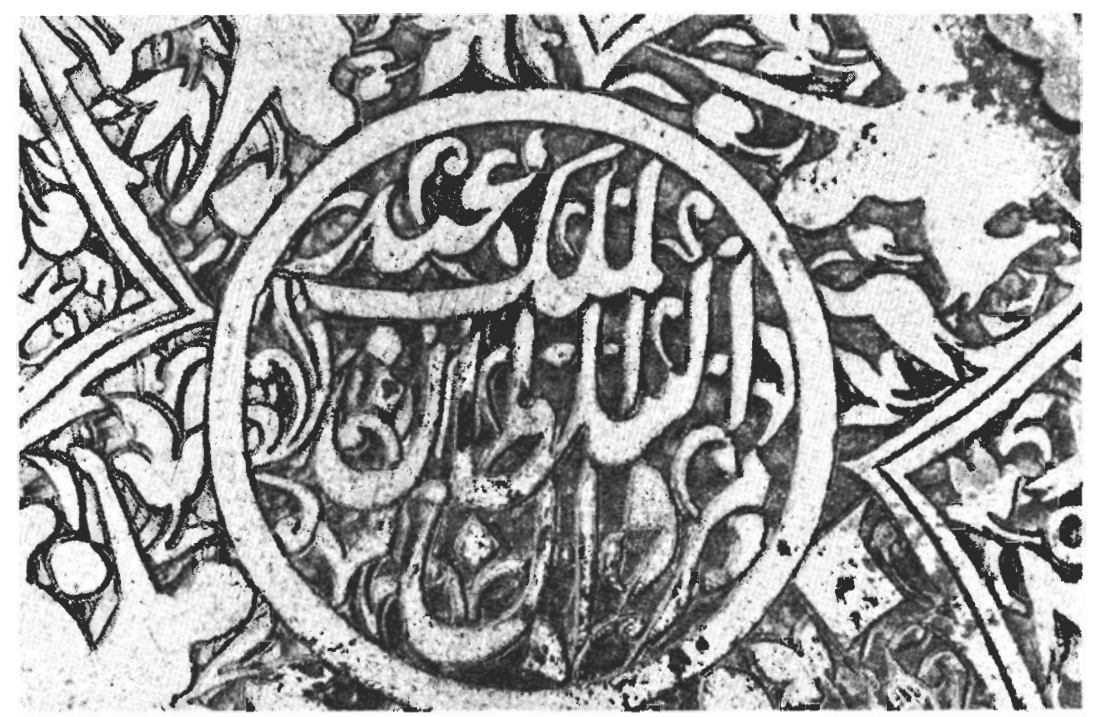

FIG. 4

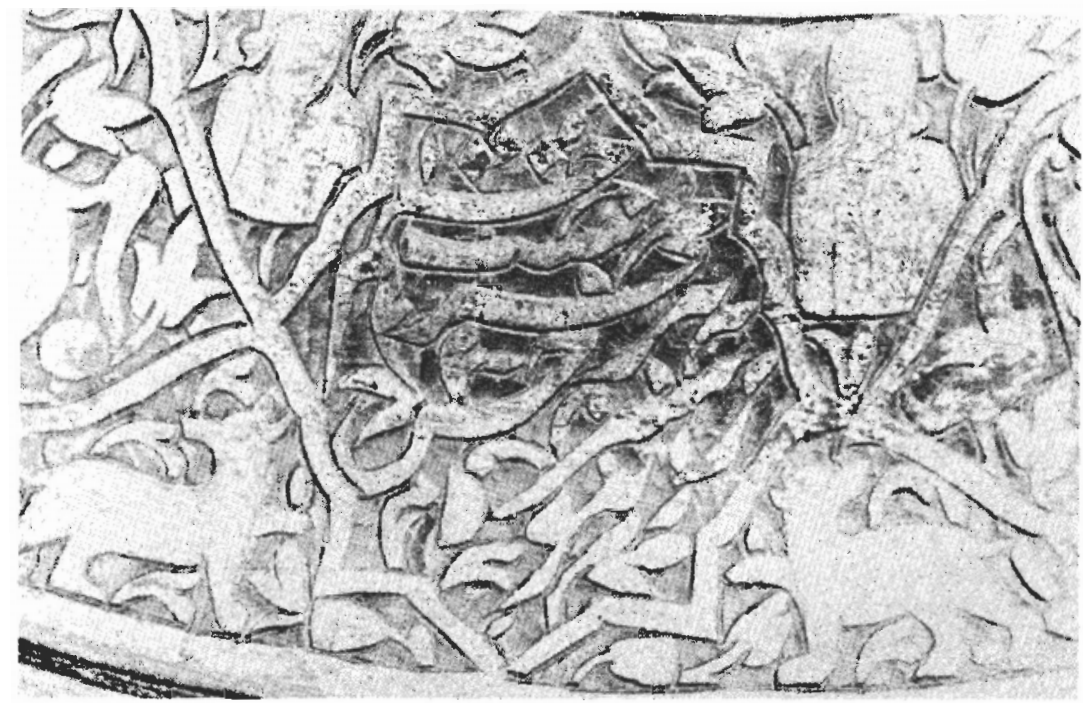

FIG. 5 a 


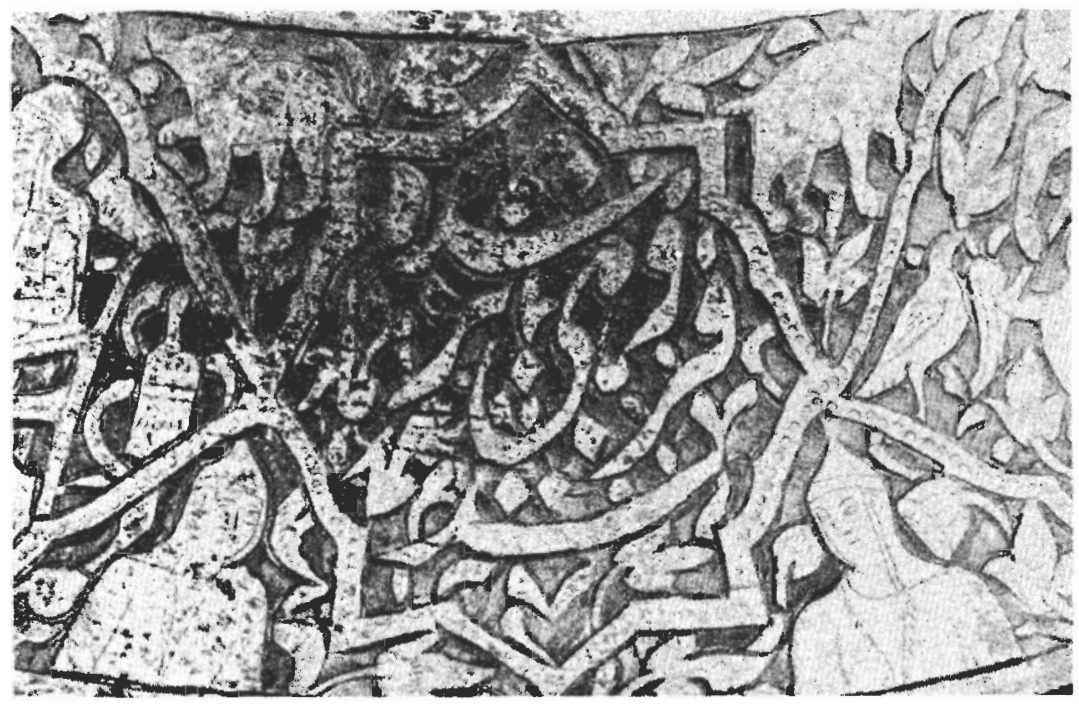

FIG. 5b

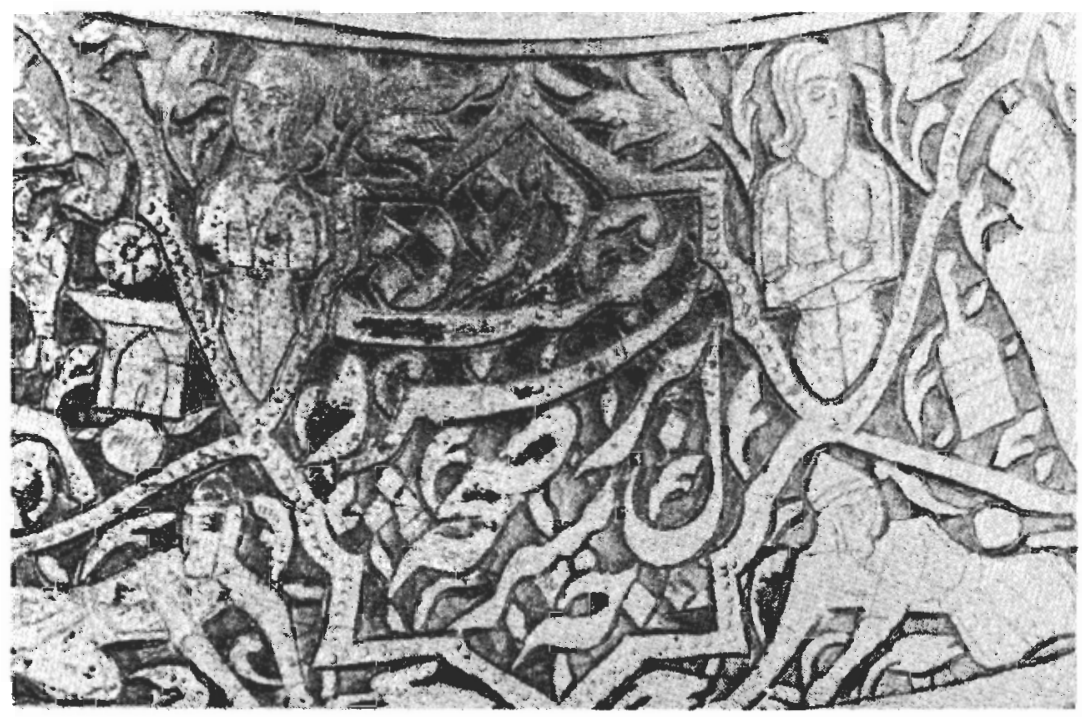

FIG. 5c 


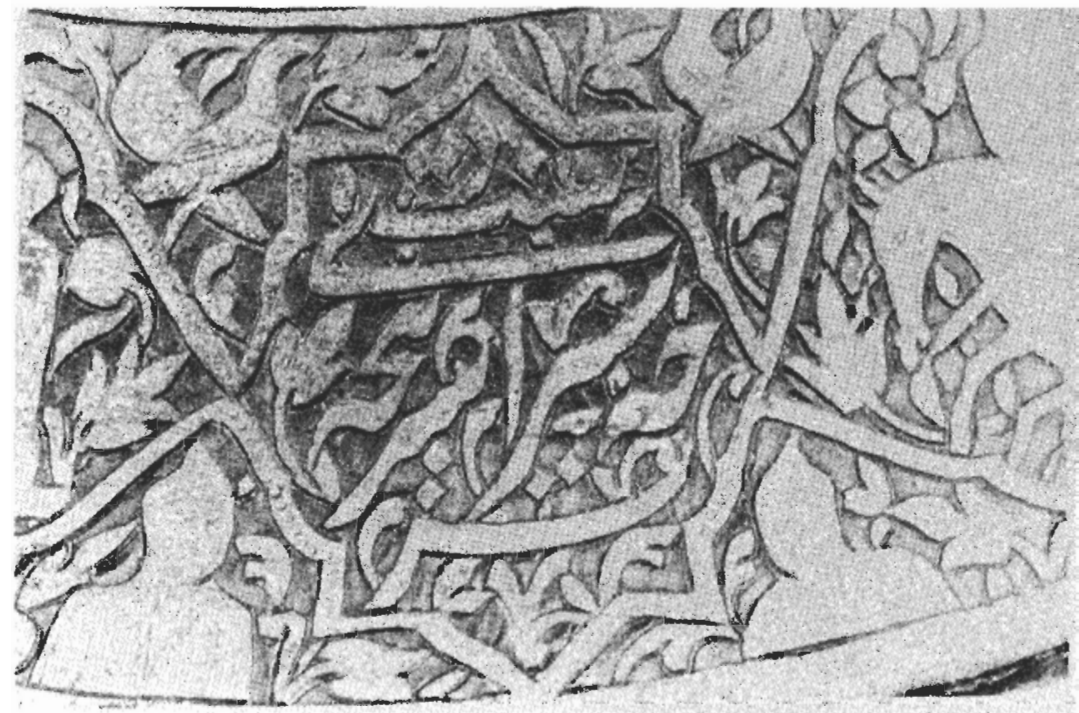

FIG. 5d

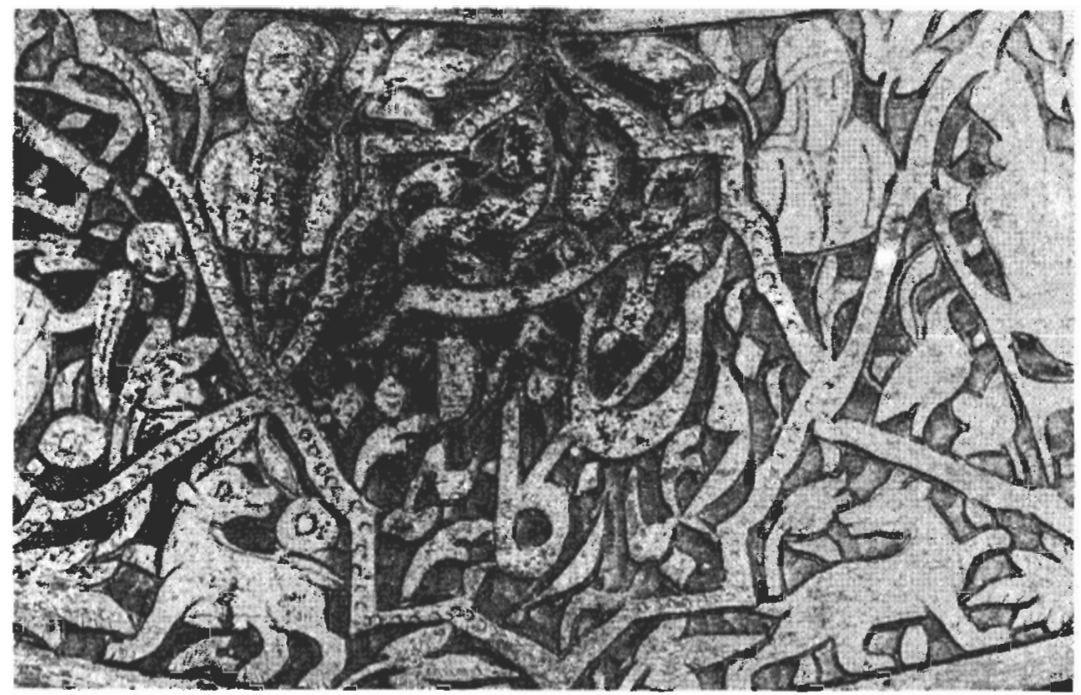

FIG. 5e 


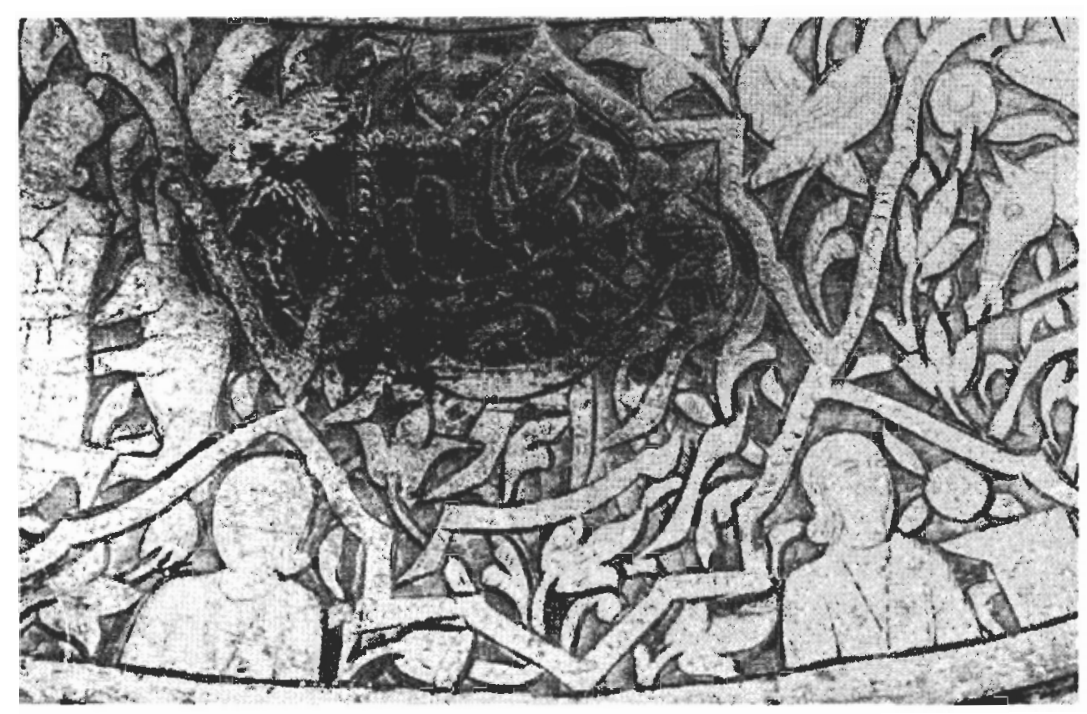

FIG. 5f

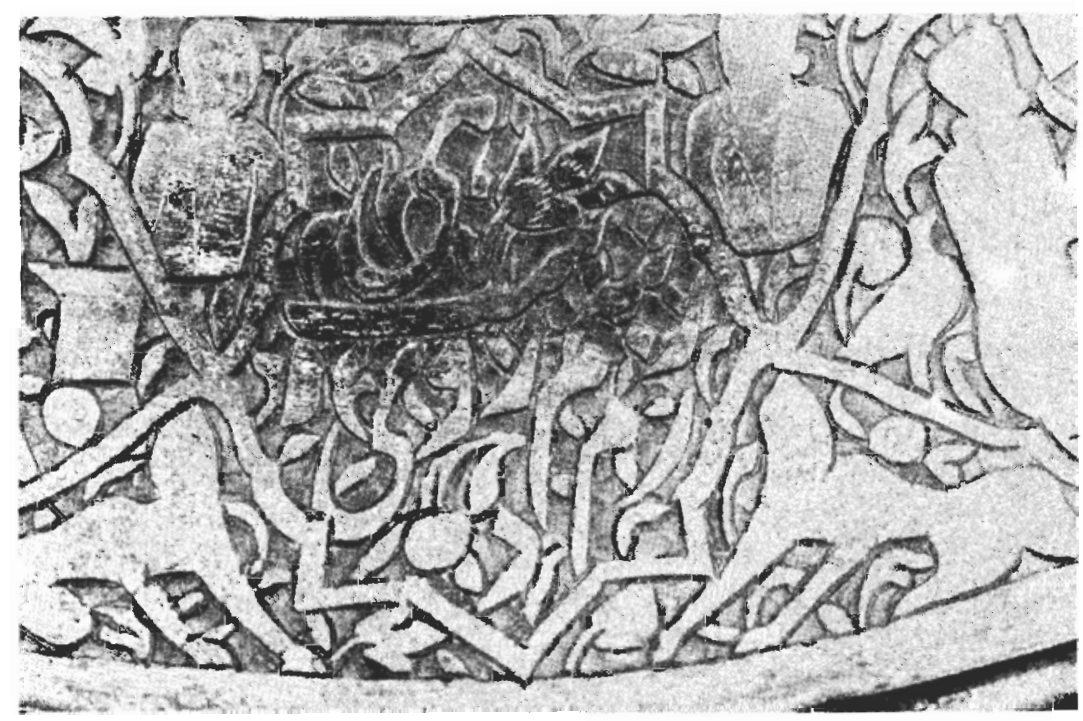

Fig. $5 g$ 


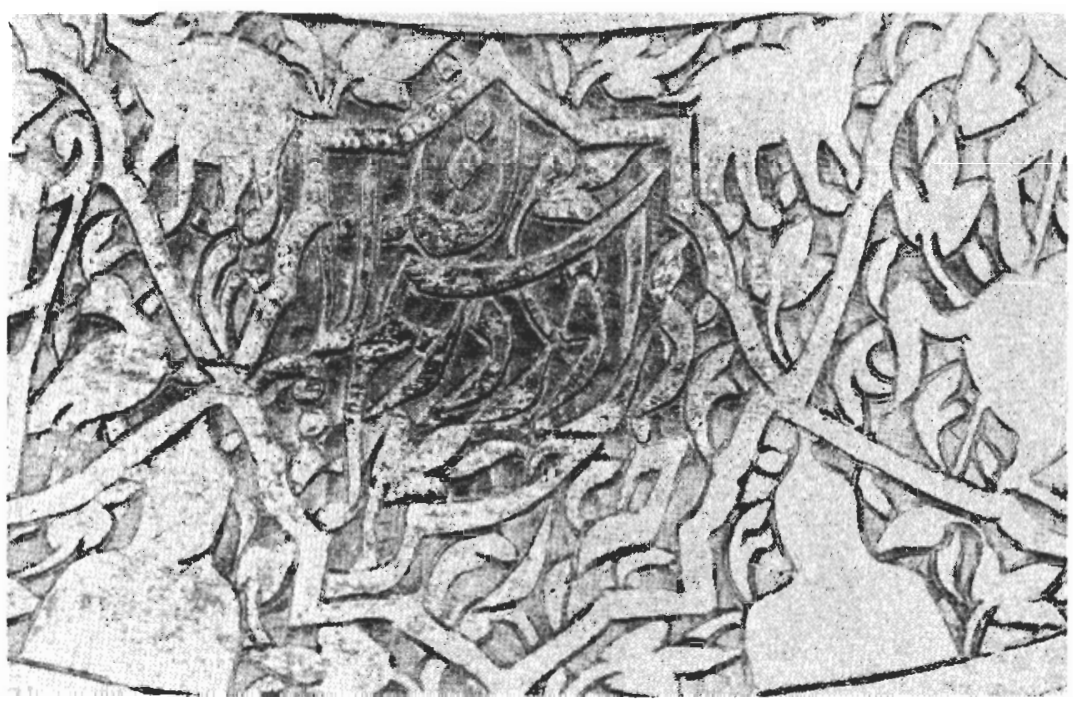

FIG. 5 h

\section{b) Casques}

No. 5 Casque en acier

Région à déterminer, XVème ou début du XVIème siècle No. d'inv. 26/125 A

\section{A la base du casque}

Dans un bandeau divisé en six cartouches; écriture cursive; caractères incrustés d'or.

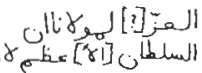

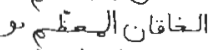

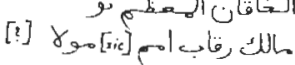

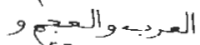

$$
\begin{aligned}
& \text { (i) }
\end{aligned}
$$

(1) Puissance à notre maître (deux lettres)

(2) le sultan [très] grand (trois lettres) 

(3) ḩāqān auguste (deux lettres)
(4) souverain des nuques des nations, maître
(5) des Arabes et des non-Arabes
(6) ombre de Dieu sur [la t]erre

\section{Sur les flancs}

Bandeau continu, très endommagé; écriture cursive; caractères en réserve sur un fond doré.

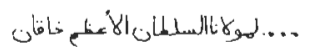

... à notre maître le sultan très grand, bुāqān

L'inscription contient la titulature d'un souverain dont le nom n'est pas mentionné. On y retrouve, comme sur le bouclier no. 1, les titres al-buāqān al-mu'azzam et mälik ruqāb al-umam ${ }^{9}$. Mais cette titulature est plus développée et contient également le titre mawlā (?) al-arab wa l-ağam, qui d'après al-Bāšā n'est attesté dans l'épigraphie que dans une inscription du sultan Malikšāh ${ }^{10}$, ainsi que le titre zillu l-lābi fī l-ard, employé par le sultan Baybars (658-676/1260-1277) ${ }^{11}$. Un titre très proche, zillu l-läbi fí ardi-bi, était porté par le sultan mamelouk al-Nāṣir Muhammad b. Qalā'ūn (693-694/1294-1295, 698-708/1299-1309 et $709-741 / 1309-1340)^{12}$.

\section{No. 6 Casque en acier}

Région à déterminer, XVème ou début du XVIème siècle

No. d'inv. 26/142 A; provient de l'Arsenal de Ste. Irène à Istanbul

$$
\text { I. Près du sommet du timbre }
$$

Dans un bandeau circulaire; écriture cursive; caractères damasquinés d'argent, sur une surface dorée.

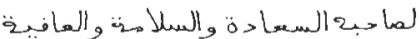

$$
\begin{aligned}
& \text { و }
\end{aligned}
$$

A son possesseur bonheur, salut, intégrité et durée de la vie, tant que la colombe roucoulera.

' Cf. le commentaire pour le bouclier no. 1, ci-dessus.

${ }^{10} \mathrm{Al}-\mathrm{B} \overline{\mathrm{A}} \mathrm{S} \overline{\mathrm{A}}$, op. cit., p. 519.

"At AL-B⿳亠̄⿵ $\bar{A}$, op. cit., p. 384.

AL A $-\bar{B} \bar{S} \bar{A}$, op. cit., p. 384. 
II. Sur les flancs dans la partie inférieure du casque

Dans un large bandeau cotinu commençant à droite de l'emplacement du nasal, aujourd'hui disparu (côté désigné du point de vue de celui qui porte le casque); écriture cursive; caractères damasquinés d'argent, sur une surface dorée.

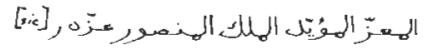

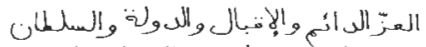

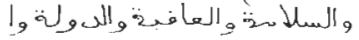

Celui qui donne la force, assisté (de Dieu), roi victorieux-que [Dieu] le rende puissant! Puissance éternelle, bonne fortune, pouvoir, force, salut, intégrité et pouvoir.

Souhaits en faveur d' un propriétaire anonyme, ainsi que quelques titres sans aucun nom, titres qu'on rencontre souvent à l'époque mamelouk (à l'exception d'al-mu'izz).

\section{No. 7 Casque en acier}

Région à déterminer, XVème ou début du XVIème siècle

Château de Windson, no. d'inv. 8 - prêté par Sa Majesté la Reine; provient de l'Arsenal de Ste. Irène à Istanbul

A la base du timbre, dans la bordure.

Bandeau contenant une inscription en écriture cursive; caractères damasquinés d'or.

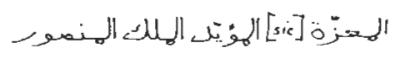

Celui qui donne la force, assisté (de Dieu), roi victorieux.

Quelques titres anonymes - à comparer avec le casque précédent.

\section{No. 8 Casque en acier}

Turquie, début du XVIème siècle

No. d'inv. 26/115 A; provient de l'Arsenal de Ste. Irène à Istanbul

I. Sur l'extrémité supérieure du nasal

Dans un registre, écriture cursive présentant une composition décorative où l'on tente d'obtenir un encadrement symétrique par deux hampes hautes dans chaque moitié du registre, reliées dans leurs extrémités 
supérieures à deux autres hampes hautes dans l'autre moitié; sans points; contours des caractères gravés.

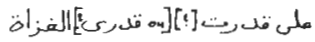

Pour la force (?) des guerriers (Fig. 6).

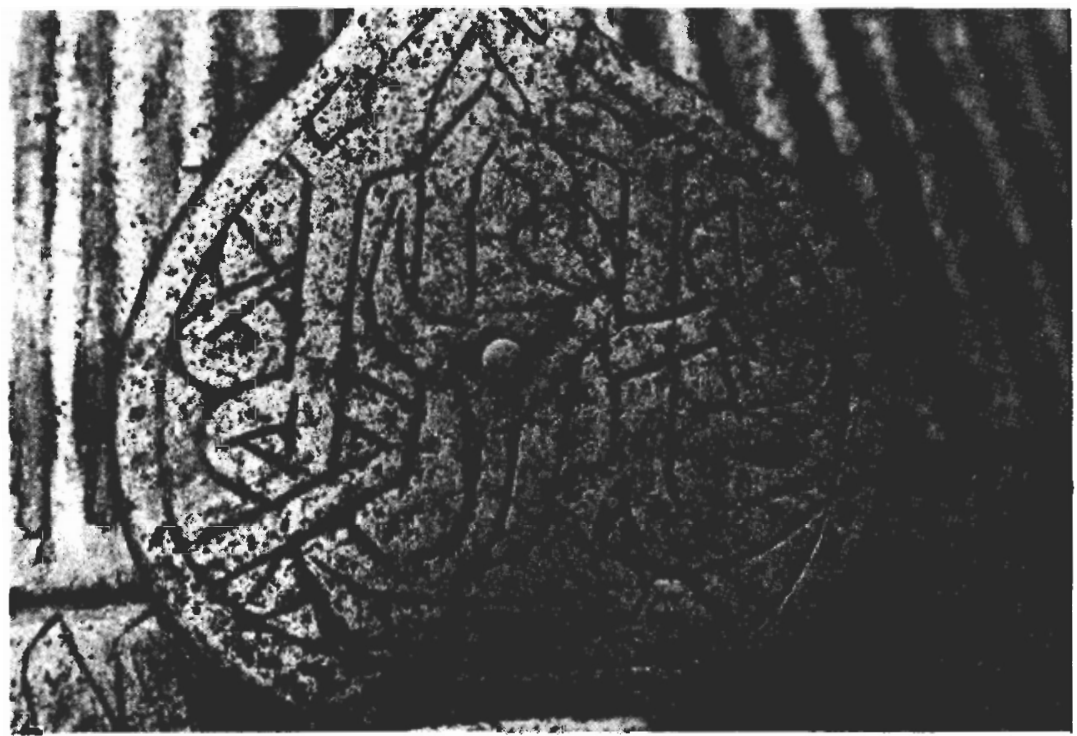

FIG. 6

II. A la base du timbre

Bandeau continu en écriture cursive; sans points; caractères gravés.

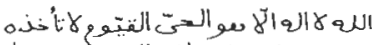

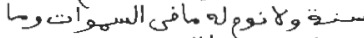

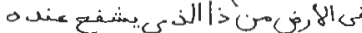

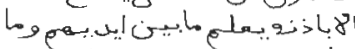

$$
\begin{aligned}
& \text { co }
\end{aligned}
$$

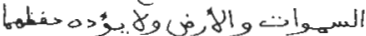

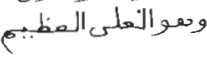

«Dieu - nulle Divinité excepté Lui-, est le Vivant, le Subsistant. $\mathrm{Ni}$ somnolence ni sommeil ne Le prennent. A Lui ce qui est dans les 
cieux et ce qui est sur la terre. Quel est celui qui intercédera auprès de Lui, sinon sur Sa permission? Il sait ce qui est entre les mains des [Hommes] et derrière eux, alors qu'ils n'embrassent de $S_{a}$ science, que ce qu'Il veut. Son Trône s'étend sur les cieux et la terre. Le conserver ne Le fait point ployer. Il est l'Auguste, l'Immense» (Cor. II, 256/255).

III. Sur le timbre, près du sommet

Bandeau circulaire continu contenant une inscription en écriture cursive; caractères gravés. Très effacé.

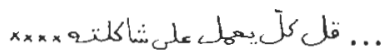

... Dis: «Chacun agit selon son mouvement» (Cor. XVII, 86/84)

IV. Sur la visière

Registre horizontal; écriture cursive; caractères gravés; quelques points.

$$
\begin{aligned}
& \text { اللح نورالسهوات والأرن بلثيل نورة }
\end{aligned}
$$

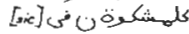

«Dieu est la Lumière des cieux et de la terre. Sa Lumière est à la ressemblance d'une niche où...» (Cor. XXIV, 35).

\section{Sur le couvre-nuque}

Dans un registre horizontal; écriture cursive; caractères gravés; quelques points.

Non lu, car très peu lisible, mais il est fort probable qu'il s'agisse d'un verset coranique.

Versets coraniques, avec une courte inscription attirant la puissance des guerriers.

\section{No. 9 Casque en acier}

Région à déterminer (Egypte ou Turquie), fin du XVème ou début du XVIème siècle

Sans no. d'inv. (actuellement dans les réserves du musée); provient de l'Arsenal de Ste. Irène à Istanbul 


\section{Sur le couvre-nuque}

Dans un registre, écriture cursive; caractères délimités sur la surface par les contours gravés, la surface des caractères était jadis dorée.

$$
\text { نمان }
$$

«Secours de Dieu et prochain succès! Annonce la bonne nouvelle aux Croyants!» (Cor. LXI, 13) O Muhammad! Dieu est véridique.

\section{A la base du timbre, dans la bordure}

Dans un bandeau continu; écriture cursive; caractères délimités sur la surface par les contours gravés, la surface des caractères étaî jadis dorée.

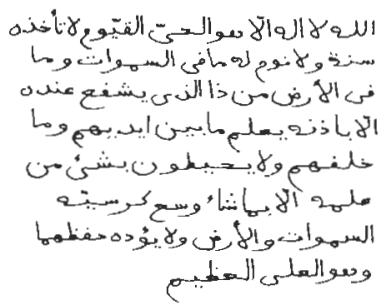

«Dieu —nulle Divinité excepté Lui-, est le Vivant, le Subsistant. $\mathrm{Ni}$ somnolence ni sommeil ne Le prennent. A Lui ce qui est dans les cieux et ce qui est sur la terre. Quel est celui qui intercédera auprès de Lui, sinon sur Sa permission? Il sait ce qui est entre les mains des [Hommes] et derrière eux, alors qu'ils n'embrassent de Sa science, que ce qu'Il veut. Son Trône s'étend sur les cieux et la terre. Le conserver ne Le fait point ployer. Il est l'Auguste, l'Immense» (Cor. II, 256/255).

Versets coraniques souvent employés sur les armes.

No. 10 Casque en acier

Iran, XVII-XVIIIème siècle

Château de Windsor, no. d'inv. 92 - prêté par Sa Majesté la Reine

I. Sur les deux extrémités du nasal, en haut (A) et en bas (B)

Trois (A) et trois (B) lignes en écriture cursive; caractères damasquinés d'or. 


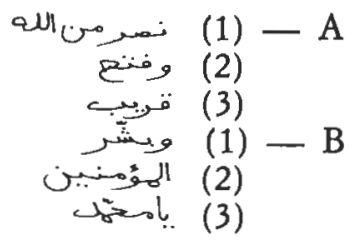

A - «Secours de Dieu et prochain succès!

B - Annonce la bonne nouvelle aux Croyants!» (Cor. LXI, 13). O Muhammad! ·

\section{A la base du timbre}

Dans une bordure divisée en six cartouches; deux lignes ( $a$ et $b$ ) dans chaque cartouche; écriture cursive; caractères damasquinés d'or.

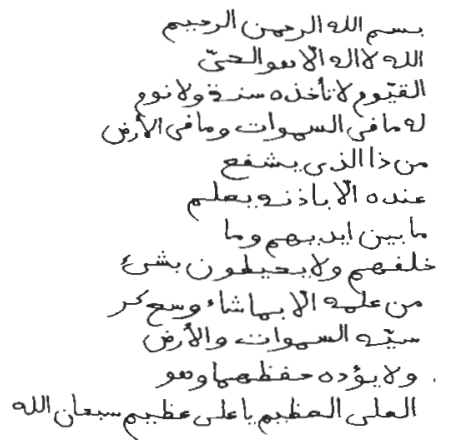

Au nom de Dieu le Clément le Miséricordieux! «Dieu -nulle Divinité excepté Lui-, est le Vivant, le Subsistant. Ni somnolence ni sommeil ne Le prennent. A Lui ce qui est dans les cieux et ce qui est sur la terre. Quel est celui qui intercédera auprès de Lui, sinon sur Sa permission? Il sait ce qui est entre les mains des [Hommes] et derrière eux, alors qu'ils n'embrassent de Sa science, que ce qu'Il veut. Son Trône s'étend sur les cieux et la terre. Le conserver ne Le fait point ployer. Il est l'Auguste, l'Immense» (Cor. II, 256/255). O Auguste, Immense! Gloire à Dieu!

Versets coraniques souvent employés sur les armes. 
No. 11 Casque en acier

Inde, XVIII-XIXème siècle

No. d'inv. 26/112 A

Sur les deux extrémités du nasal, en haut (A) et en bas (B).

Trois (A) et quatre (B) lignes en écriture cursive; caractères en réserve sur un fond doré.

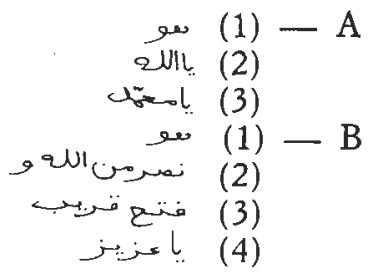

A - Lui. O Dieu! O Muhammad!

$\mathrm{B}$ - Lui. «Secours de Dieu et prochain succès!» (Cor. LXI, 13) O Puissant!

Invocations religieuses et citation coranique.

No. 12 Casque en acier

Iran, première moitié du XIXème siècle

Château de Windsor, no. d'inv. 82 — prêté par Sa Majesté la Reine

I. Près du sommet du timbre

Dans un bandeau circulaire; caractères angulaires damasquinés d'or, très hétéroclytes et très effacés - lecture impossible.

\section{Sur les flancs}

Dans un cartouche à gauche $(\mathrm{A})$ et dans un cartouche à droite (B) du nasal (côtés désignés du point de vue de celui qui porte le casque); trois lignes à lire de haut en bas $(\mathrm{A})$ et trois lignes à lire de bas en haut (B); écriture cursive (ta'liq); caractères damasquinés d'or.

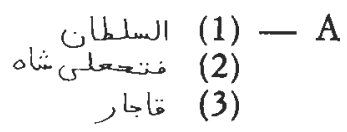




\section{onim (3) - B \\ [rie] ureb

A - Sultan Fatḥ’alī Šàh Qāgāàr.

B - Tahmāsp, serviteur du Roi de l'Amitié divine.

III. A la base du timbre, dans la bordure

Bandeau continu; écriture cursive; caractères damasquinés d'or.

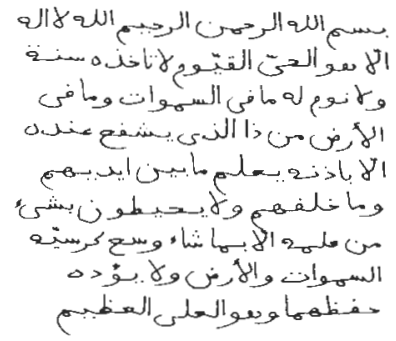

Au nom de Dieu le Clément le Miséricordieux! «Dieu —nulle Divinité excepté Lui-, est le Vivant, le Subsistant. Ni somnolence ni sommeil ne Le prennent. A Lui ce qui est dans les cieux et ce qui est sur la terre. Quel est celui qui intercédera auprès de Lui, sinon sur Sa permission? Il sait ce qui est entre les mains des [Hommes] et derrière eux, alors qu'ils n'embrassent de Sa science, que ce qu'Il veut. Son Trône s'étend sur. les cieux et la terre. Le conserver ne Le fait point ployer. Il est l'Auguste, l'Immense» (Cor. II, 256/255).

A côté du verset coranique «āyat al-kursì», l'un des versets les plus souvent employés sur les armes, on lit sur les flancs le nom de Fath'alī Šāh Qāḡār, au pouvoir en Iran entre les années 1211/1797 et 1250/ 1834. Le deuxième personnage mentionné est le šāh safavide Tahmāsp (930/1524-984/1576), la présence de son nom sur le casque avait un caractère «sacré».

No, 13 Casque en acier (à deux cornes)

Iran, début du XIXème siècle

No. d'inv. 26/133 A

A la base du timbre, dans la bordure.

Huit grands cartouches alternant avec sept petits cartouches; écriture cursive ( $\left.t^{\top} l \bar{l} q\right)$; caractères en relief damasquinés d'argent. 
L'inscription contient une copie incomplète et imprécise des vers qui suivent, répartis dans les quinze cartouches d'une façon irrégulière. Certains mots manquent.

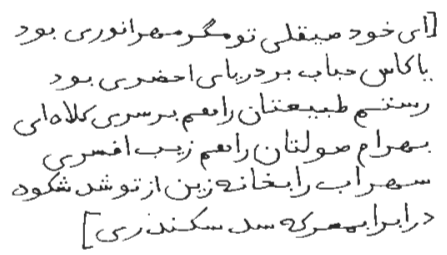

[O casque chatoyant, tu es peut-être le soleil très brillant

$\mathrm{Ou}$ tu es une coupe de bulle sur l'océan vert

Tu es la coiffe sur la tête des gens du caractère de Rostam

Pour ceux qui ont la bravoure de Bahrām tu es l'ornement du diadème Grâce à toi Sohräb a reçu la grandeur en selle

Tu es pour Darius dans la bataille le barrage d'Alexandre]

\section{No. 14 Casque en acier}

Iran, début du XIXème siècle

No. d'inv. 26/130 A

A la base du timbre, dans la bordure.

Quatre cartouches; écriture cursive ( $\operatorname{ta}^{c} l \bar{i} q$ ); caractères ciselés et dorés. L'inscription commence à droite du nasal (côté désigné du point de vue de celui qui porte le casque). La fin du troisième et le quatrième cartouches sont recouverts par le porte-aigrette.

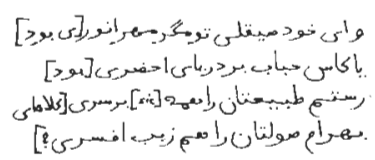

$\mathrm{O}$ casque chatoyant, tu es peut-être le soleil très brillant

Ou tu es une coupe de bulle sur l'océan vert

[Tu es la coiffe] sur la tête des gens au caractère de Rostam

[Pour ceux qui ont la bravoure de Bahrām tù es l'ornement du diadème]

Vers persans souvent employés sur les casques fabriqués en Iran au XIXème siècle. 
No. 15 Casque en acier

Iran, XIXème siècle

No. d'inv. 26/132 A

A la base du timbre, dans la bordure.

Six grands cartouches alternant avec six petits cartouches; écriture cursive ( $t a^{\prime} l \bar{\imath} q$ ); caractères damasquinés d'argent.

L'inscription contient une copie incomplète et imprécise des vers qui suivent, répartis dans les douze cartouches d'une façon très irrégulière. Certains mots manquent.

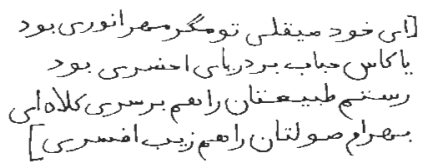

[O casque chatoyant, tu es peut-être le soleil très brillant

$\mathrm{Ou}$ tu es une coupe de bulle sur l'océan vert

Tu es la coiffe sur la tête des gens du caractère de Rostam

Pour ceux qui ont la bravoure de Bahrām tu es l'ornement du diadème ]

Vers persans souvent employé sur les casques fabriqués en Iran, éventuellement en Inde, au XIXème siècle. Les copies successives, exécutées souvent par des artisans illetrés, ont eu pour conséquence l'éloignement du texte original et un grand nombre d'erreurs. Cf. les casques nos. 13 et 14 .

\section{c) Armure}

No. 16 Armure en acier, composée de quatre éléments

Iran, $1213 / 1798$

No. d'inv. $26 / 72$ A

Plaque couvrant la poitrine, à décor laqué.

Dans la partie supérieure, dans un cartouche en forme de losange polylobé; cinq lignes en écriture cursive, au-dessous la date; caractères appliqués au pinceau.

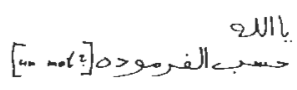




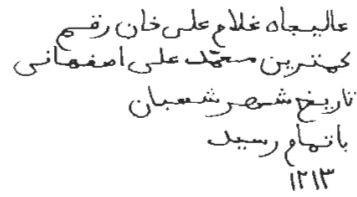

O Dieu! A été exécuté conformément à l'ordre de l'élevé en dignité Gulām 'Alī Ḩān; dessin du plus humble Muhammad 'Alī Ișfahānī; à la date du mois de ša'bān 1213/janvier 1799 (Fig. 7).

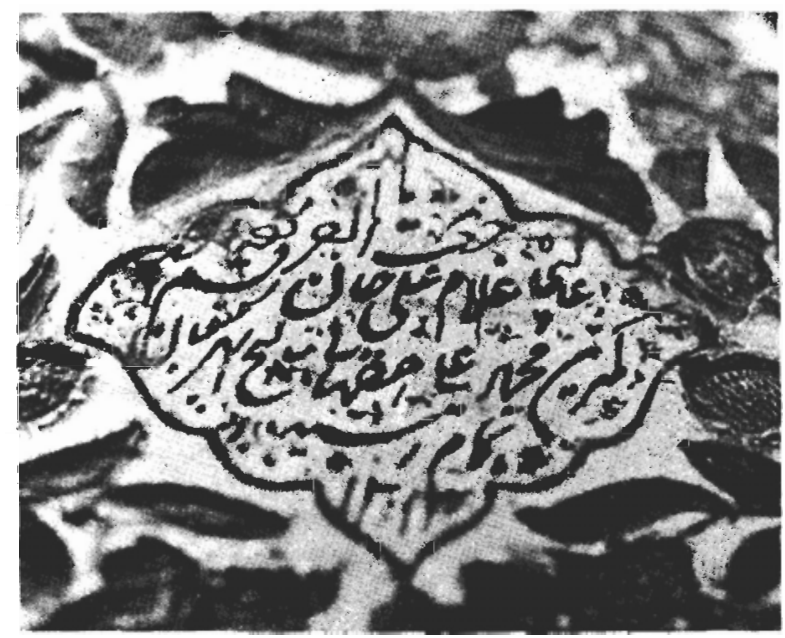

FIG. 7

Signalé dans L. A. Mayer, Islamic Armourers and their works, Genève, 1962 , p. 57 , où l'on indique également d'autres références bibliographiques.
d) Cotte de maille

No. 17 Cotte de maille

Région à déterminer, fin du XVème siècle (?)

No. d'inv. 26/113 A; provient de l'Arsenal de Ste. Irène à Istanbul

Sur chaque maille.

Une ligne en écriture cursive; sans points; poinçonnée. 


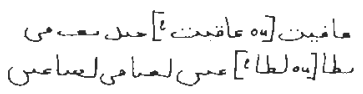

L'inscription est à caractère talismanique. Seul le premier mot a pu être déchiffré, il s'agit peut-être du mot intégrité. Mais on pourrait éventuellement le lire 'äqiba, c'est-à-dire fin, suivi peut-être du mot bayr (bonté, bon). Pour la suite, les points diacritiques n'ont pas pu êtrc complétés, mais tenant compte de la répétition de certains groupes de caractères qui rappellent des formules talismaniques ${ }^{13}$ et du fait que la présence de ces formules ne soit pas étonnante sur une cotte de maille ${ }^{14}$, il faut sans doute orienter les futures tentatives de déchiffrement dans ce sens.

\section{e) Chantrein}

\section{No. 18 Chanfrein en acier}

Région à déterminer, XVème ou début du XVIème siècle No. d'inv. $26 / 3 \mathrm{H}$

I. Sur les deux côté du chanfrein, à droite (A) et à gauche (B)

Un bandeau de chaque côté; écriture cursive; caractères délimités sur la surface par les contours gravés, la surface des caractères est argentée (partiellement effacé); fond rempli d'un rinceau floral gravé.

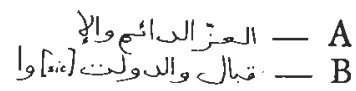

Puissance éternelle, bonne fortune, pouvoir.

${ }^{13}$ Cf. par exemple Edmond DoutTe, Magie E religion dans l'Afrique du Nord, Alger, 1909, surtout les pp. 143-218; H. A. WINKLER, Siegel und Charaktere in der mubammedanischen Zauberei, Berlin et Leipzig, 1930, surtout les pp. 26-37; T. CANAAN, The Decipberment of Arabic Talismans, dans Beryutus, IV, 1937, pp. 69-110 et pp. 141-151; Rudolf KRIss et Hubert Kriss-Heinrich, Volksglaube im Bereich des Islam, t. II: Amulette, Zauberformeln und Beschwörungen, Wiesbaden, 1962, à plusieurs endroits; J. Marques-Rivière, Amulettes, talismans et pantacles dans les traditions orientales et occidentales, Paris; 1972, pp. 124-128 et pp. 135-137.

${ }^{14} \mathrm{Cf}$. par exemple Walther Rose, Die Verzierungen auf orientalischen Panzerbemden, dans Zeitschrift für bistorische Waffenkunde, I, 1897-99, pp. 142-144 et 166-167; ID., Die Verzierung altorientalischer Panzerringe, dans ibid., III, 1902 . 1905, pp. 8-15. 
II. Au sommet du chanfrein, sur une bossette

Bandeau circulaire; écriture cursive; caractères délimités sur la surface par les contours gtavés, la surface des caractères est argentée; fond rempli d'un rinceau floral gravé.

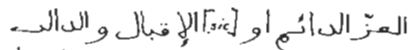

$$
\begin{aligned}
& \text { [السولة }
\end{aligned}
$$

Puissance éternelle, bonne fortune, pouvoir, bonheur.

III. Au sommet du chanfrein, autour de la bossette

Bandeau circulaire; écriture cursive; caractères délimités sur la surface par les contours gravés, la surface des caractères est argentée; fond rempli d'un décor floral gravé.

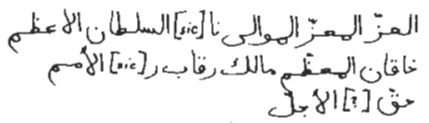

Puissance [à] celui qui donne la force, notre maître, le sultan très grand, hãqān auguste, souverain des nuques des nations, vérité (?) très illustre.

Souhaits en faveur d'un propriétaire anonyme. Quelques titres sans nom propre, qu'on peut comparer avec les titres dans la bordure du bouclier no. 1 et du casque no. 5 (voir le commentaire pour ces deux objets). La lecture du mot baqq n'est pas certaine, même si elle correspond à la graphie. Le fait que ce mot soit le titre d'un souverain serait très surprenant, ce mot étant souvent employé pour désigner Dieu.

\section{ARMES}

a) Sabres

No. 19 Sabre à poignée de type «talwar»

Inde, XVII-XVIIIème siècle (la lame est du XVIIème siècle, la poignée du XVIIIème siècle)

No. d'inv. $9 / 800$

Sur le côté extérieur de la lame.

Neuf registres en écriture cursive ( $t a^{\prime} l \bar{l} q$ ); caractères damasquinés d'or; le fond est décoré d'un décor floral et figuratif très fin. 


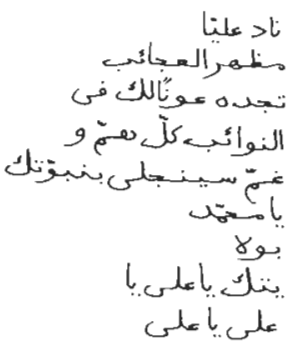

Invoque 'Alī, qui fait paraître les prodiges

$\mathrm{Tu}$ le trouveras secourable dans le malheur

Toute angoisse, tout chagrin se dissiperont

Par ta qualité de Prophète, ô Muhammad, par ta qualité d'Ami de Dieu, ô 'Alī, ô 'Alī, ô 'Alī

Quatrain à tendance shi'ite fréquent sur les armes ainsi que sur d'autres objets d'art de cette période. Cf. aussi no. 23.

No. 20 Sabre

Iran, $1186 / 1772$

No. d'inv. $26 / 161 \mathrm{~S}$

Sur le côté extérieur de la lame, en partant de la poignée:

I. Dans un cartouche ovale pointu surmonté sur la pointe d'un fleuron symétrique; écriture cursive ( $t a^{\imath} T_{i} q$ ), à lire de bas en haut, dans un ordre irrégulier; caractères damasquinés d'or

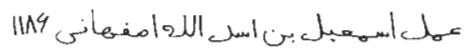

Oeuvre de Ismāîl b. Asad Ailāh Iṣfahānī, 1186/1772 (Fig. 8a)

II. A gauche de la partie supérieure du cartouche précédent, dans un carré partagé par une ligne verticale et une ligne horizontale en quatre compartiments. Un caractère en écriture cursive dans chaque compartiment; damasquiné d'or

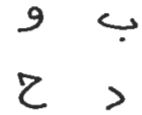




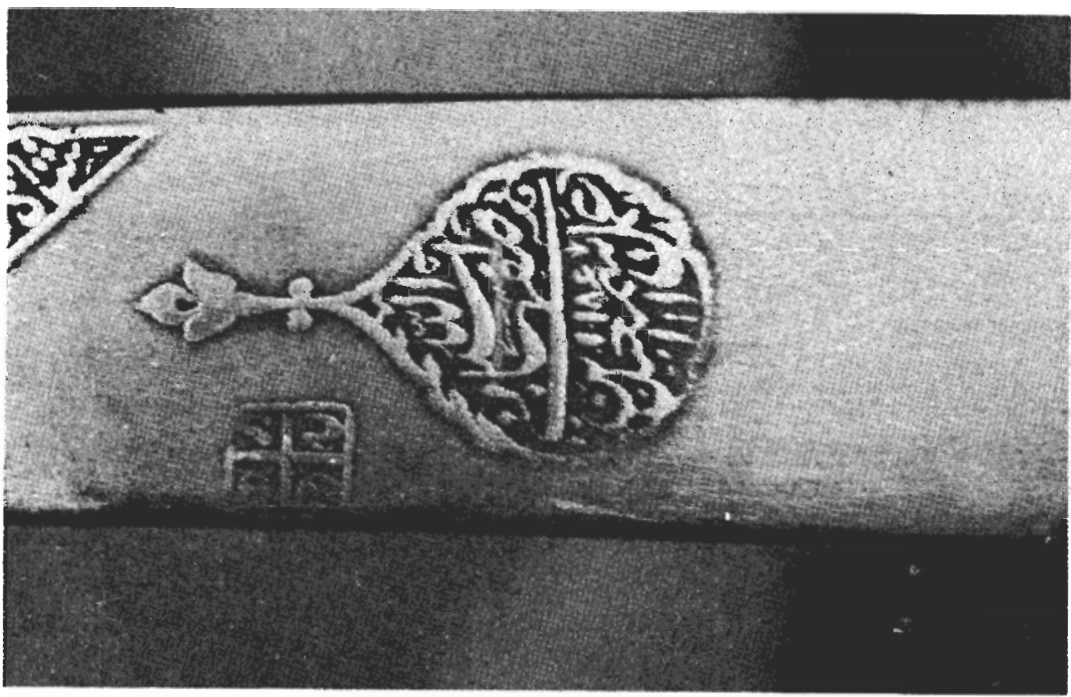

FIG. 8a

III. Dans trois cartouches superposés, en forme d'un parallélogramme; une ligne dans chaque cartouche; écriture cursive ( $\operatorname{ta}^{x}(\bar{i} q)$; dama,quinée d'or

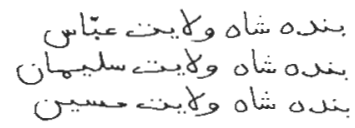

(1) 'Abbās, serviteur du Roi de l'Amitié divine

(2) Sulaymān, serviteur du Roi de l'Amitié divine

(3) Husayn, serviteur du Roi de l'Amitié divine (Fig. 8b)

IV. Dans la gouttière le long du dos, dans deux cartouches allongés aux côtés latéraux en forme d'un lobe; une ligne en écriture cursive dans chaque cartouche; caractères damasquinés d'or

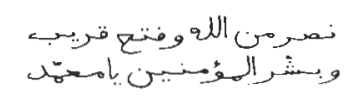

«Secours de Dieu et prochain succès! Annonce la bonne nouvelle aux Croyants!» (Cor. LXI, 13). O Muhammad! (Fig. 8b et c). 


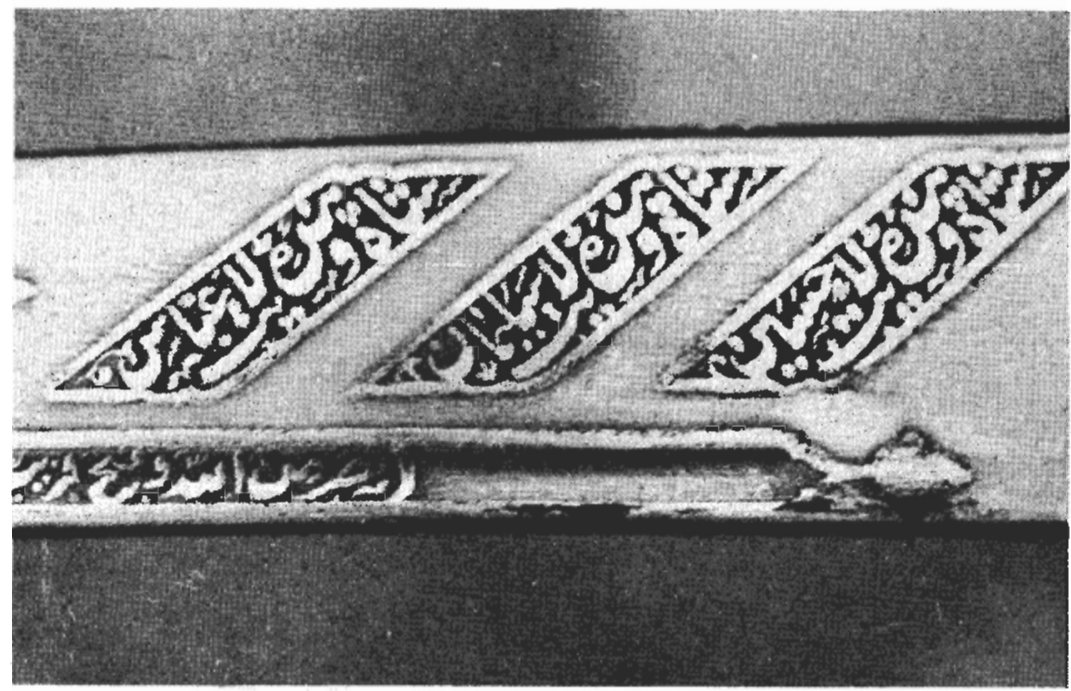

FIG. 8b

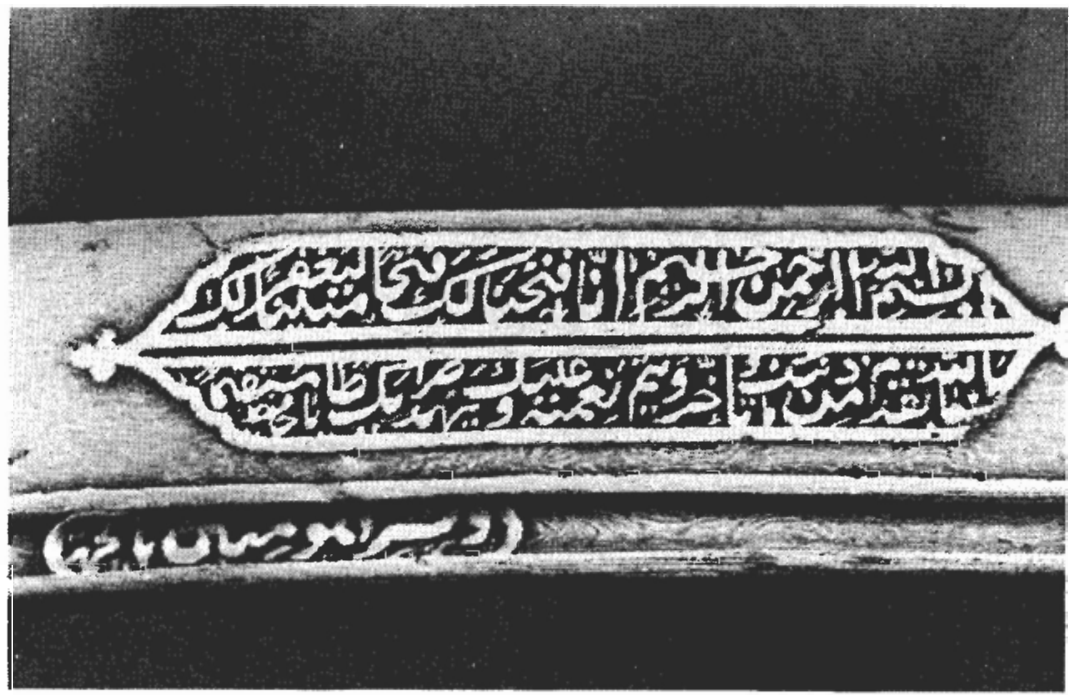

FIG. 8c 
V. Dans un cartouche allongé aux côtés latéraux polylobés, partagé en deux compartiments superposés par deux lignes droites parallèles et horizontales. Une ligne dans chaque compartiment; écriture cursive; caractères damasquinés d'or

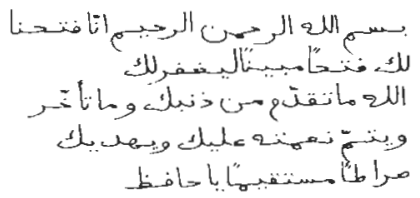

«Au nom de Dieu le Clément le Miséricordieux! En vérité, Nous t'avons octroyé un succès éclatant, afin que Dieu te pardonne tes premiers et tes derniers péchés, qu'Il parachève Son bienfait envers toi et qu'Il te dirige dans une Voie Droite» (Cor. XLVIII, 1-2). O Gardien! (Fig. 8c).

A côté des versets coraniques qu'on trouve fréquemment sur les armes, on remarque la présence des noms de trois šăhs safavides qui sont 'Abbās, Sulaymān et Husayn. Chaqun porte le titre «serviteur du Roi de l'Amitié divine» et leur présence ici doit attirer la protéction de l'usager du sabre. Le «carré magique», contenant le mot badzub, a un caractère talismanique. L'armurier est le fils du célèbre Asad Allāh Iṣfahānī ${ }^{15}$. Cf. le commentaire pour le sabre no. 30, ci-dessous.

\section{No. 21 Sabre à poignée de typè «talwar»}

Inde, fin du XVIIIème siècle

No. d'inv. 26/115 S (actuellement dans les réserves)

Sur le côté extérieur de la lame.

A) Dans un cartouche ovale pointu aux deux extrémités, dans lequel est inscrit un autre cartouche en forme de fuseau dont les deux côtés latéraux sont identiques à une partic du cartouche extérieur.

I. Dans les quatre segments entre les contours des deux cartouches; écriture cursive; points; caractères gravés

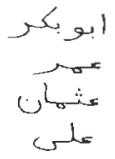

${ }^{15}$ Le même artisan est signalé dans L. A. MAYer, Islamic Armourers and their Works, Genève, 1962, p. 44: "Isma'îl b. Asad Allah Ișfahânî, at an unspecified date, made ('amal) a sword, now in the Royal Collection at Windsor, n..$^{\circ}$ 1788.» 

(1)'Ábū Bakr
(2) 'Umar
(3) 'Utmān
(4) 'Alī (Fig. 9)

II. A l'intérieur du cartouche intérieur; cinq lignes en écriture cursive; points; caractères gravés

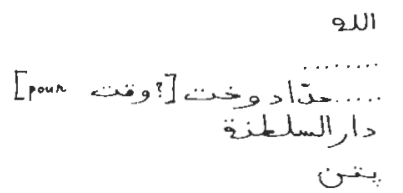
(1) Dieu
(2) $\ldots$
(3) ... forgeron du temps (?)
(4) Dār al-salțana (Maison du Gouvernement)
(5) «La Ville» ${ }^{16}$ (Fig. 9)

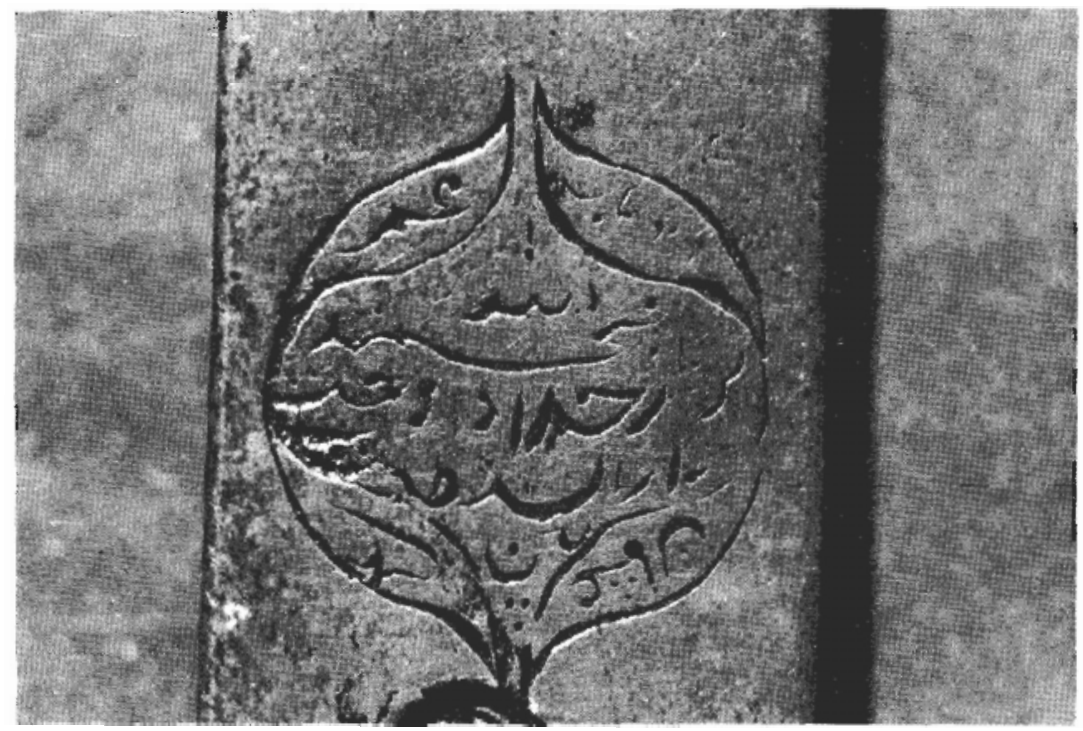

Fig. 9 .

th Le mot «la Ville" désigne la ville de Seringapatam, capitale de Tipu Sultan. Cf. John Allan, Catalogue of the Coins in the Indian Museum Calcutta, t. IV, Oxford, 1928 , p. 69. 
B) Près de la partie inférieure dı cartouche; poinçon; écriture cursive.

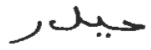

inte

Haydar (surnom de Tipu Sultan) $1227 / 1799^{17}$

L'inscription contient les noms des quatre premiers caliphes, connus sous le nom d'al-bulatā' al-rāšidün. A l'intérieur du cartouche, le nom de l'artisan n'a pas été lu, mais nous apprenons que le sabre a été fabriqué à Seringapatan, capitale de Tipu Sultan ${ }^{18}$, en 1799 . Le poinçon de l'arsenal de Tipu Sultan confirme les renseignements précédents. Cf. le fusil no. 39 fabriqué également à Seringapatan, à la même période.

No. 22 Sabre de type «šamšir»

Iran, XVIIIème siècle

No. d'inv. 26/12 S (actuellement dans les réserves)

Sur le côté extérieure de la lame.

I. Dans un espace entre le motif décoratif et le bandeau contenant l'inscription no. II; écriture cursive ( $\left.t a^{\prime} l \bar{l} q\right)$; caractères incrustés d'argent

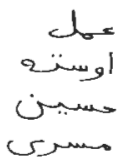

(1) Oeuvre

(2) du maître

(3) Husayn

(4) Mustī (Fig. 10)

${ }^{17}$ La date est exprimée en ère Mawludi, introduite par Tipu Sultan. Cette ère commence l'année de la naissance du Prophète et le calandrier est luni-solaire, avec une année de douze mois lunaires et des mois intercalés par intervales. Avec l'introduction de ce système on a également changé l'ordre des chiffres qui commencent à droite et non à gauche comme c'est l'usage. Cf. John Allan, Catalogue of the Coins in the Indian Museum Calcutta, t. IV, Oxford, 1928, p. 71.

${ }^{18}$ Cf. ci-dessus, la note no. 15. 


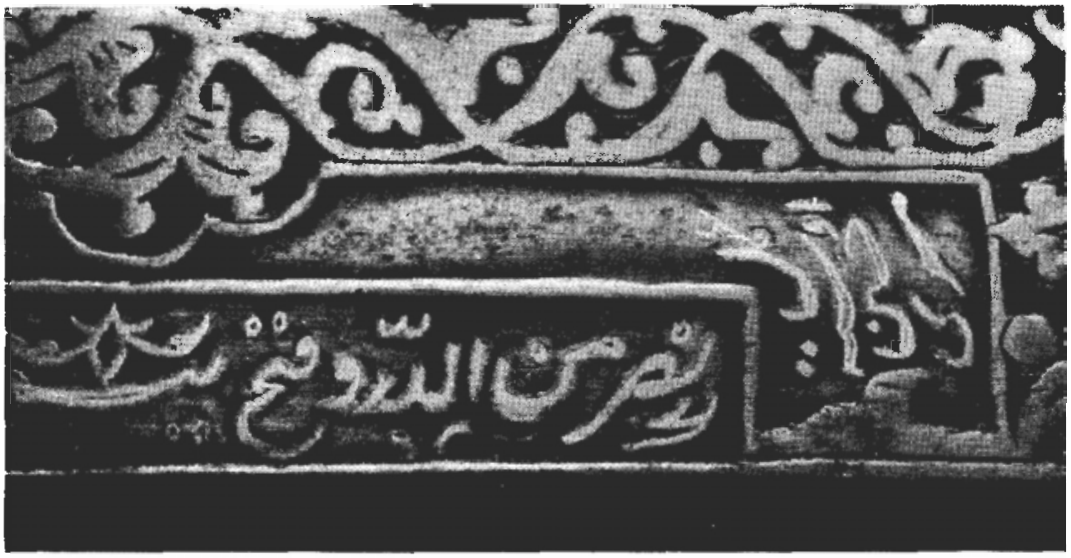

Fig. 10

II. Dans un bandeau longeant le tranchant; écriture cursive (ta'lī); caractères incrustés d'argent

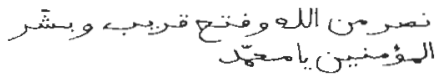

«Secours de Dieu et prochain succès! Annonce la bonne nouvelle aux Croyants!» (Cor. LXI, 13) O Muhammad!

Texte coranique fréquent sur les armes et signature d'un artisan non signalée dans L. A. Mayer, Islamic Armourers and their works, Genève, 1962.

No. 23 Sabre à poignée de type «talwar»

Inde (Maratha), XVIIIème siècle

No. d'inv. 26/1 S

\section{Sur le côté extérieur de la lame}

Deux lignes horizontales (A 1-2) et deux courtes lignes verticales à la fin des deux lignes horizontales (B 1-2); écriture cursive ( $t a^{\top} t \bar{q} q$ ); caractères gravés et damasquinés d'or; le fond est argenté.

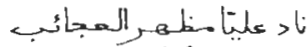

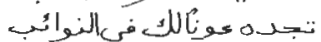




$$
\begin{array}{ll}
\text { (1) } & \text { (1) } \\
\text { اكب़ر (2) }
\end{array}
$$

A - (1) Invoque 'Alī, qui fait paraître les prodiges

(2) Tu le trouveras secourable dans le malheur

$\mathrm{B}-\quad$ Dieu est Très-Grand

II. Sur le côté intérieur de la lame

Deux lignes horizontales; écriture cursive ( $t a^{\imath} l \bar{q} q$ ); caractères gravés et damasquinés d'or; le fond est argenté.

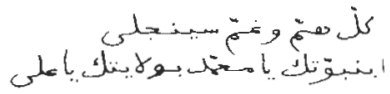

(1) Toute angoisse, tout chagrin se dissiperont

(2) Par ta qualité de Prophète, ô Muhammad, par ta qualité d'Ami de Dieu, ô "Alì

Quatrain à tendance shi'ite fréquent sur les armes de cette période. Cf. no. 19.

No. 24 Epée

Inde, XVIII-XIXème siècle

No. d'inv. 26/88 S

A) Sur la lame, côté intérieur.

I. Dans deux compartiments ornementaux, près de la poignée, à gauche (1) et à droite (2) de la croix de la garde; écriture cursive (talliq); caractères incrustés d'or sur un fond à décor floral doré

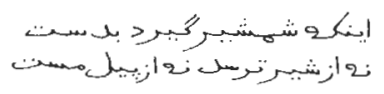

(1) Celui qui prend le sabre à la main

(2) Ne craint ni un lion, ni un éléphant déchaîné

II. Plus loin après l'inscription no. I; écriture cursive ( $t a^{c} l i \bar{q}$ ); caractères incrustés d'or

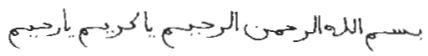


Au nom de Dieu le Clément le Miséricordieux. O Généreux! O Miséricordieux!

B) Sur la lame, côté extérieur.

I. Dans deux compartiments ornementaux, près de la poignée, à gauche (1) et à droite (2) de la croix de la garde, écriture cursive ( $\left.t a^{\prime} l i ̄ q\right)$; caractères incrustés d'or sur un fond à décor floral doré. Une partie de la deuxième ligne est cachée para la croix

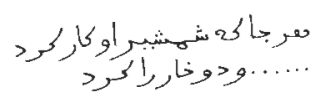

(1) Où que ce soit que son sabre agisse

(2) ... et coupe l'épine en deux

II. Plus loin, après l'inscription no. I; écriture cursive (táliq); caractères incrustés d'or

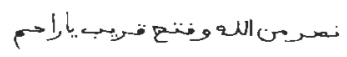

«Secours de Dieu et prochain succès!» (Cor. LXI, 13) O Clément!

Vers persans louant les qualités du sabre, verset coranique fréquent sur les armes, la basmala et quelques invocations de Dieu employant «les flus beaux noms de Dieu».

No. 25 Sabre

Lame fabriquée à Londres par Wilkinson; décorée en Inde en 1847, pour le 1er Lord Hardinge of Penshurst

No. d'inv. 26/39 S

Sur la lame, côté extérieur.

Dans un cartouche composé de deux compartiments rectangulaires superposés, flanqués à droite et à gauche d'un trapèze régulier présenté verticalement. Une ligne dans chaque rectangle (A 1-2); dans les trapèzes à droite $(\mathrm{B})$ et à gauche $(\mathrm{C})$ une date. Écriture cursive (talìq); points; caractères damasquinés d'or.

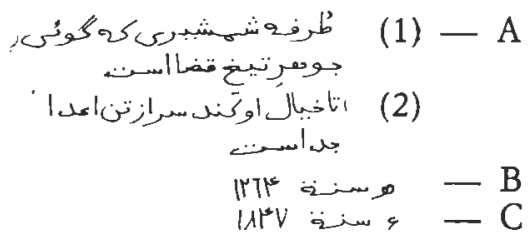


A - (1) Un regard sur le sabre dont tu dirais qu'il est le brillant de la lame du destin

(2) Qu'il imagine que la tête est séparée du corps des ennemis

B - $\quad$ Année de l'hégire 1264[/1847-48]

C - $\quad$ Année de l'ère chrétienne 1847 (Fig. 11)

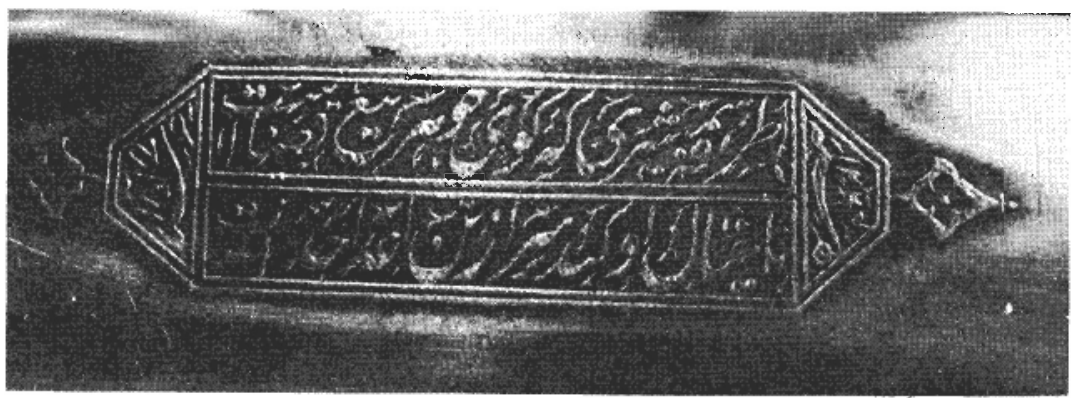

Fig. 11

Vers persans louant les qualités du sabre. A comparer avec les no. 26, 27 et 28: les inscriptions ont été exécutées dans la même année par le même artisan.

No. 26 Sabre

Lame fabriquée à Londres par Wilkinson; décorée en Inde en 1847, pour le 1er Lord Hardinge of Penshurst

No. d'inv. 26/38 S (actuellement dans les réserves)

Sur la lame, côté extérieur.

Dans un cartouche composé de deux compartiments rectangulaires superposés, flanqués à droite et à gauche d'un trapèze régulier présenté verticalement. Une ligne dans chaque rectangle (A 1-2); dans les trapèzes à droite $(\mathrm{B})$ et à gauche $(\mathrm{C})$ une date. Écriture cursive (táti $q$ ); points; caractères damasquinés d'or.

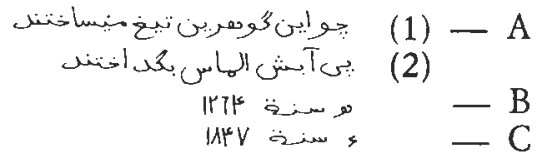


A - (1) Lorsqu'on fabriquait ce sabre précieux

(2) Pour sa trempe, ils ont liquéfié le diamant

B - $\quad$ Année de l'hégire 1264[/1847-48]

C - Année de l'ère chrétienne 1847 (Fig. 12)

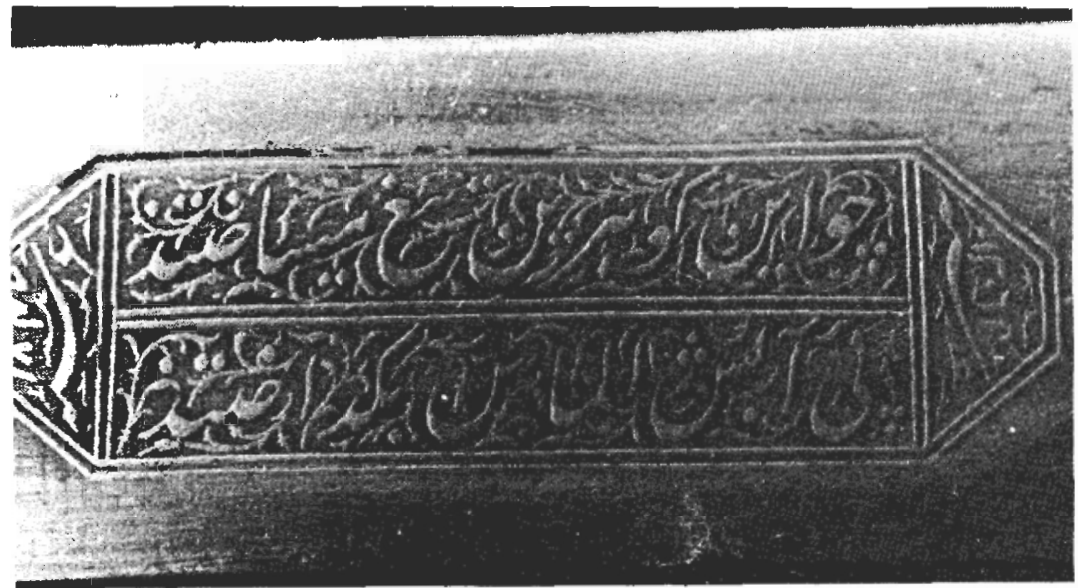

FIG, 12

Vers persans louant les qualités du sabre. A comparer avec les nos. 25, 27 et 28: les inscriptions ont été exécutées dans la même année par le même artisan.

\section{No. 27 Sabre}

Lame fabriquée à Londres par Wilkinson; décorée en Inde en 1847, pour le 1er Lord Hardinge of Penshurst

No. d’inv. 26/42 S (actuellement dans le réserves)

Sur la lame, côté extérieur.

Dans un cartouche composé de deux compartiments rectangulaires superposés, flanqués à droite et à gauche d'un trapèze régulier présenté verticalement. Une ligne dans chaque rectangle (A 1-2); dans les trapèzes à droite (B) et à gauche $(\mathrm{C})$ une date. Écriture cursive (talinq); points; caractères damasquinés d'or. 


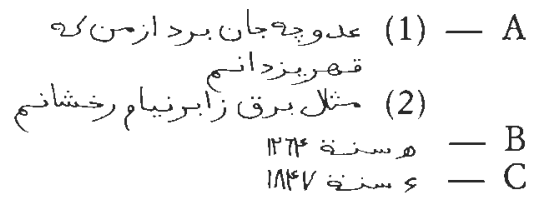

A - (1) Comment l'ennemi peut-il avoir la vie sauve de ma part, qui suis la colère de Dieu

(2) Je suis foudroyant comme l'éclair du nuage du fourreau

B - $\quad$ Année de l'hégire 1264[/1847-48]

C - $\quad$ Année de l'ère chrétienne 1847 (Fig. 13)

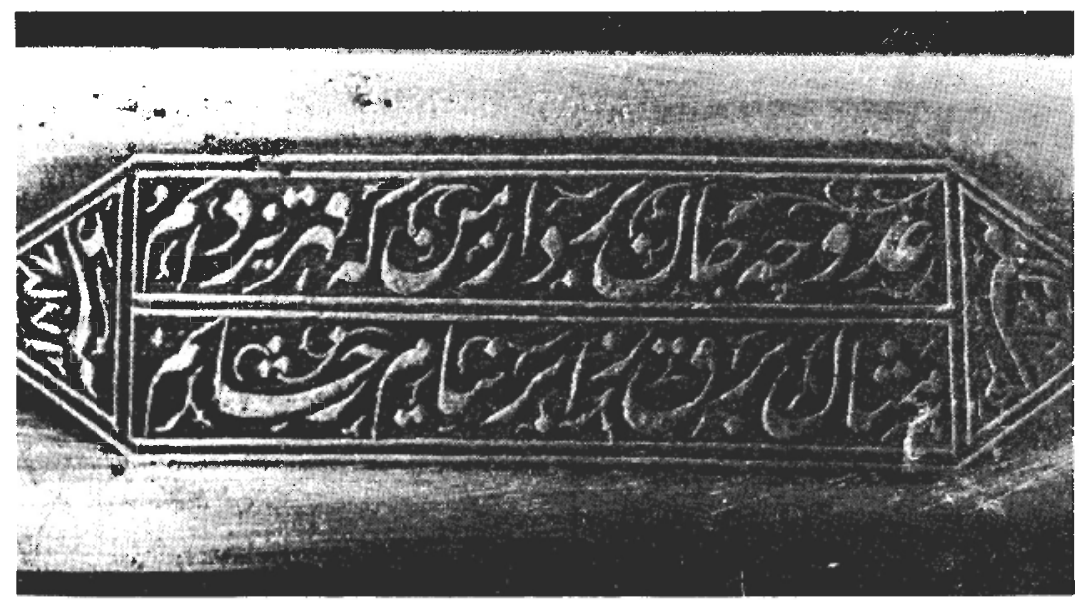

FIG. 13

Vers persans louant les qualités du sabre. A comparer avec les nos. 25, 26 et 28: les inscriptions ont été exécutées dans la même année par le même artisan.

No. 28 Sabre

Lame fabriquée à Londres par Wilkinson; décorée en Inde en 1847, pour le 1er Lord Hardinge of Penshurst

No. d'inv. 26/41 S (actuellement dans les réserves) 
Sur la lame, côté extérieur.

Dans un cartouche composé de deux compartiments rectangulaires superposés, flanqués à droite et à gauche d'un trapèze régulier présenté verticalement. Une ligne dans chaque rectangle (A 1-2); dans les trapèzes à droite $(\mathrm{B})$ et à gauche $(\mathrm{C})$ une date. Écriture cursive (talìq); points; caractères damasquinés d'or.

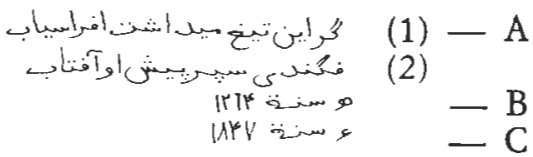
A - (1) Si Afrāsyāb avait eu ce sabre
(2) Alors le soleil aurait jeté devant lui le bouclier
B - $\quad$ Année de l'hégire 1264[/1847-48]
C - Année de l'ère chrétienne 1847 (Fig. 14)

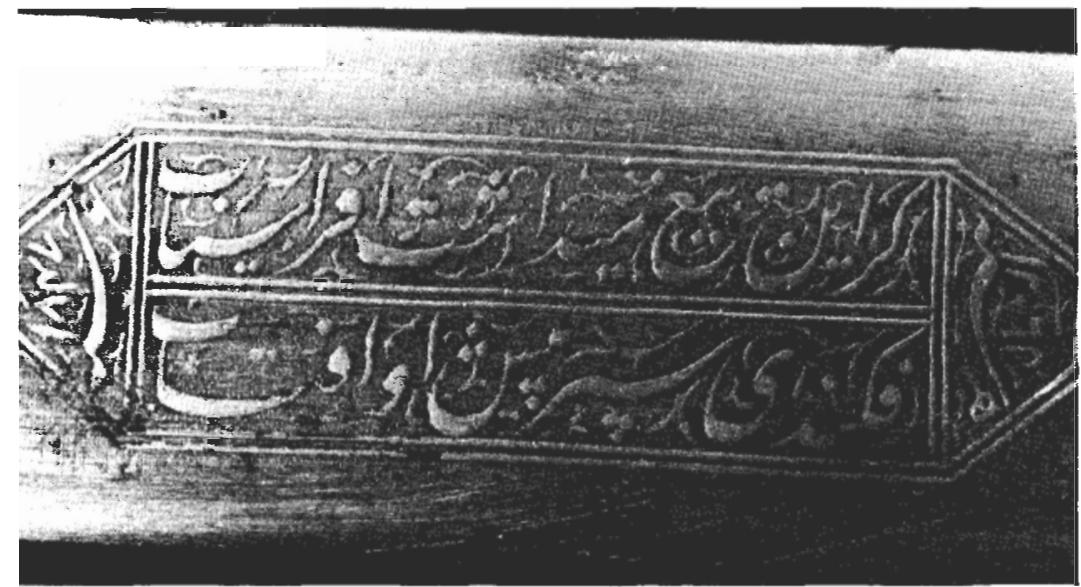

FIG, 14

Vers persans louant les qualités du sabre. A comparer avec les trois sabres précédents: les inscriptions ont été exécutées dans la même année par le même artisan. 
No. 29 Sabre de type «qiliç»

Turquie, début du XIXème siècle

No. d'inv. 26/116 S

I. Sur le côté extérieur de la lame

Bandeau épigraphique près du dos, partagé en cinq compartiments; écriture cursive; caractères incrustés d'or.

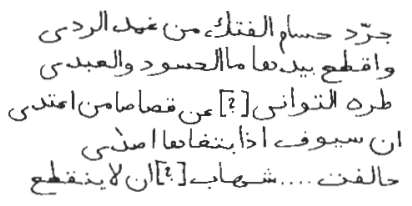

(1) Dégaîne du fourreau de la destruction le cimeterre de la temérité

(2) Et coupe par sa force ce qu'il y a d'envie et d'avidité

(3) ... (?) de la vengeance de celui qui est hostile

(4) Car les sabres, voilà que la soif les désire

(5) J'ai lié par le serment... pour qu'il ne soit pas interrompu (Figures $15 \mathrm{a}-\mathrm{d})$

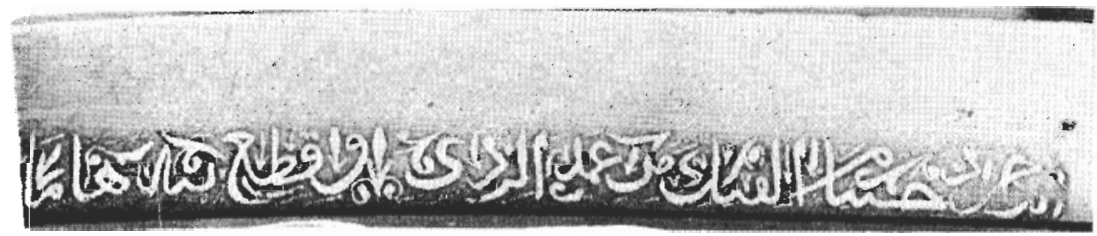

FIG. 15a

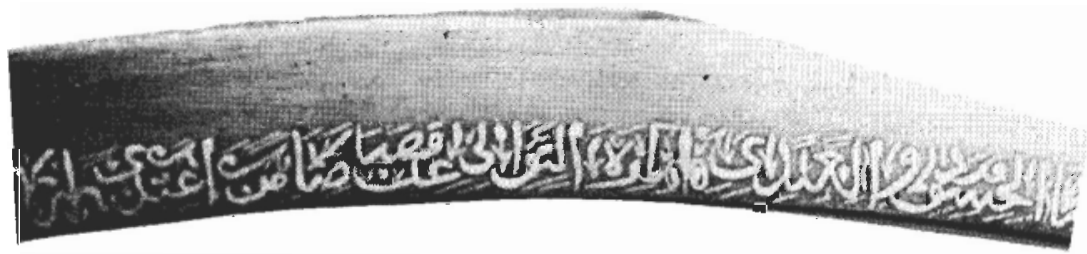

FIG. 15b 


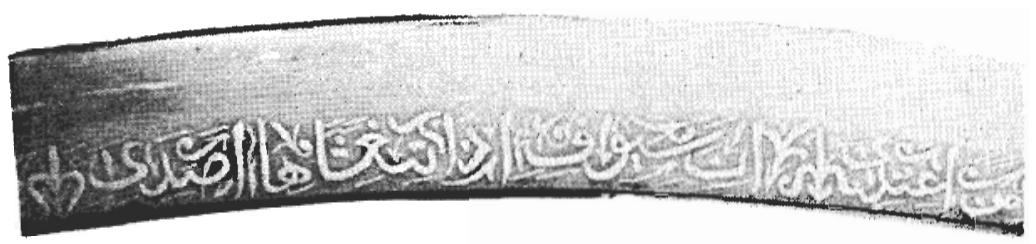

FIG. 15c

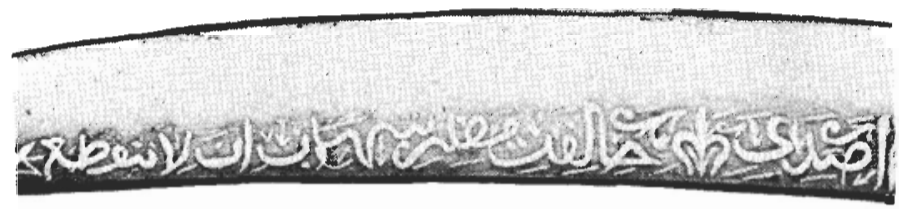

FIG. 15d

II. Sur le côté intérieur de la lame

Bandeau épigraphique près du dos, partagé en cinq compartiments; écriture cursive; caractères incrustés d'or.

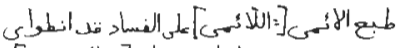

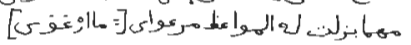

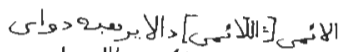

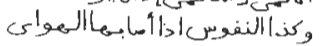

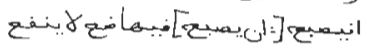

(1) ... sur l'oppression, elle est pliée

(2) Quoique tu fasses pour l'avertir, il ne s'inquiète pas

(3) ... la maladie (?) ne la craint pas

(4) Comme les âmes si la passion les atteint

(5) Et s'il devient (?), dépose, il ne servira pas (Figs. 16a-d)

L'inscription sur le côté extérieur de la lame contient quatre vers arabes concernant le sabre, plus un vers indépendant qui va avec le vers du cinquième cartouche sur le côté intérieur de la lame. Les quatre premiers cartouches de ce côté contiennent, comme c'est le cas sur le côté extérieur, quatre vers arabes dont le sens reste à compléter. La lecture des vers et leur traduction ne sont que provisoires, elles seront à com. 


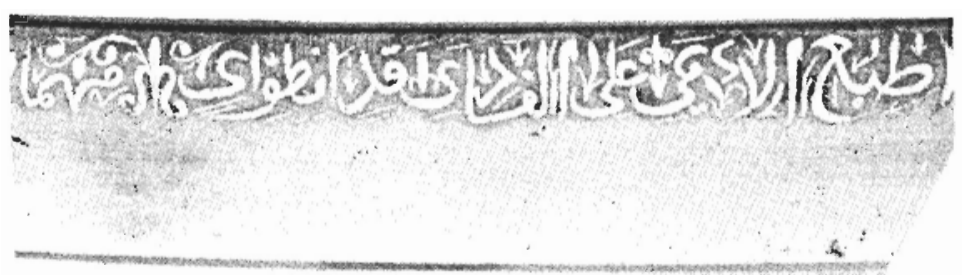

FIG. 16a

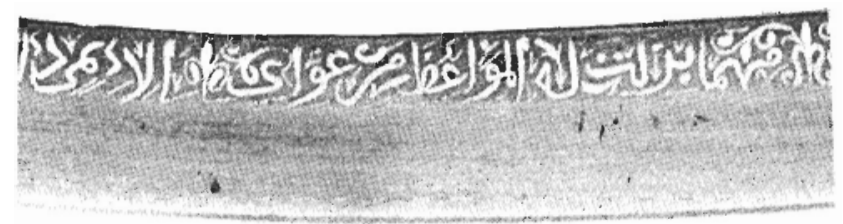

FIG. 16b

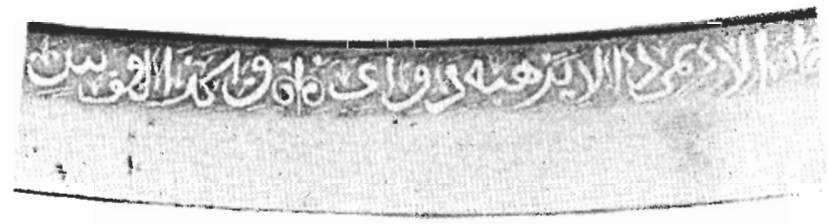

FIG. $16 c$

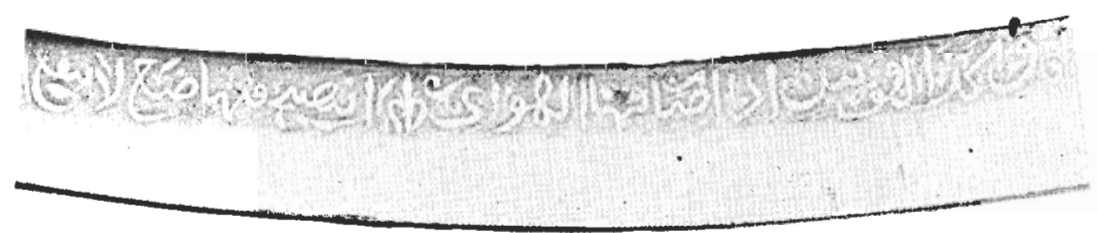

FIG. 16d 
pléter par comparaison avec d'autres objets portant la même inscription. Nous avons déjà rencontré les mêmes vers sur un sabre dans une collection privée, malheureusement il ne nous a pas été possible d'en prendre la photo ou d'en noter la lecture, même approximative. Mais ceci est au moins la preuve que cette inscription n'est pas une inscription unique.

No. 30 Sabre à poignée de type «talwar»

Inde, XIXème siècle

No. d'inv. 26/11 S

Sur le côté extérieur de la lame.

Registre à l'intérieur d'un cartouche polylobé; écriture cursive; caractères damasquinés d'or; à lire dans un ordre irrégulier.

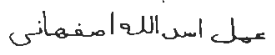

Oeuvre d'Asad Allāh Ișfahānī (Fig. 17)

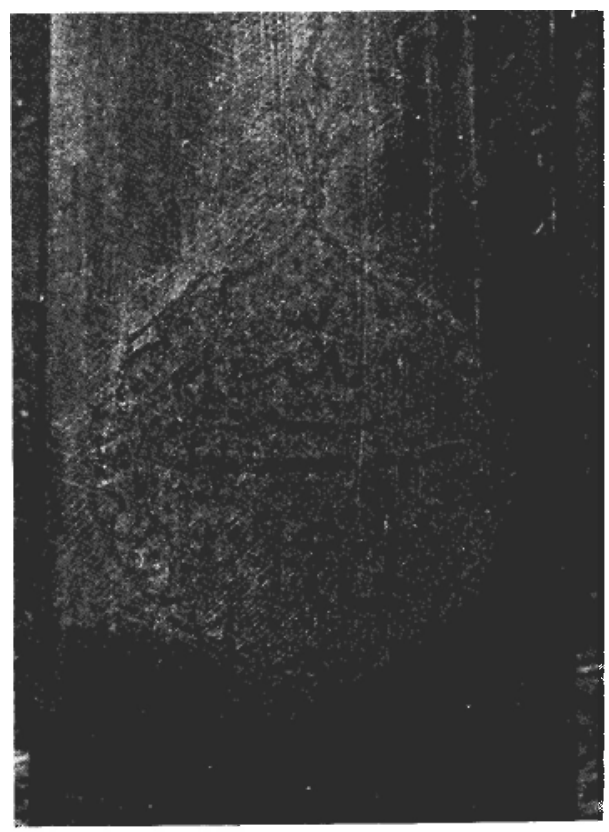

FIG. 17 
Signature du célèbre armurier Asad Allāh Ișfahānī, qui est très fréquente sur les sabres d'origine persane ou indienne, à partir du XVIIème siècle. Nous savons que ce personnage n'est pas le fabricant de toutes les lames qui portent son nom. Cf. un grand nombre de sabres avec son nom signalés dans L. A. Mayer, Islamic Armourers and their works, Genève, 1962, p. 44.

No. 31 Sabre

Inde, XIXème siècle

No. d'inv, 26/44 S (actuellement dans les réserves)

A) Sur le côté extérieur de la lame.

I. Près de la gardè

Dans un médaillon circulaire aux contours doubles, deux triangles " isocèles superposés, en position opposée forment un hexagone. Inscription à l'intérieur de l'hexagone; damasquinée d'or.

\section{Dieu था}

II. Plus loin sur la lame

Près du tranchant, trois cartouches aux côtés latéraux ovales. A l'intérieur de chaque cartouche, une ligne en écriture cursive; caractères damasquinés d'or.

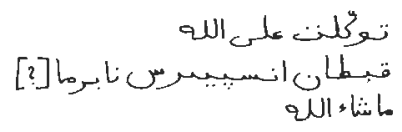

(1) Je me suis remis à Dieu

(2) Capitaine... (Fig. 18)

(3) Ce que Dieu veut

B) Sur le côté intérieur de la lame.

I. Dans un médaillon près de la garde

Deux lignes en écriture cursive; caractères damasquinés d'or; très effacé et mal exécuté. 


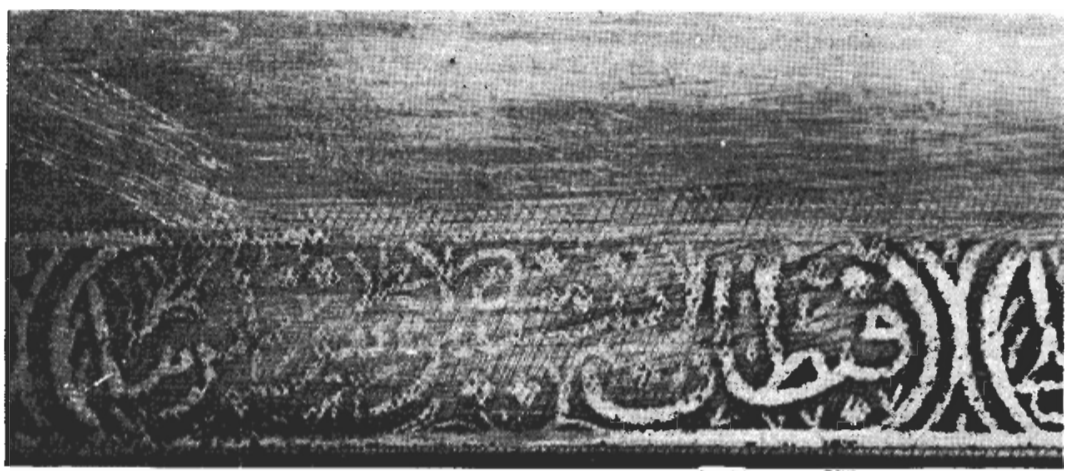

FIG. 18

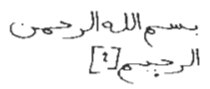

(1) Au nom de Dieu le Clément

(2) le Miséricordieux (?)

II. Un autre médaillon plus éloigné de la garde

Dans un registre; écriture cursive; caractères damasquinés d'or.

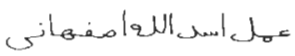

Oeuvre d'Asad Allāh Ișfahānī

C) Sur la garde, au milieu de la croix, côté intérieur.

Dans un médaillon circulaire, deux triangles isocèles superposés en position opposée forment un hexagone. Dans les angles de l'hexagone, les noms des Sept Dormants. Au milieu:

\section{O Dieu! الل}

Les inscriptions contiennent des formules religieuses et la signature du célèbre armurier Asad Allāh I:̣̂hānī, qui n'était certainement pas le fabricant de ce sabre ( $c f$. le commentaire pour le sabre précédent). Le 
nom du propriétaire est sans doute d'origine européenne, il avait le grade de capitaine.

No. 32 Sabre

Lame de fabrication italienne du XVIIème siècle; inscriptions sur la lame et la poignée rajoutées vers 1900 .

No. d'inv. 26/112 S

A) Sur le côté extérieur de la lame.

Dans un cadre rectangulaire, une ligne en écriture cursive; exécutée à l'eau forte.

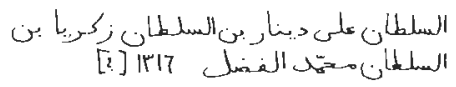

Sultan 'Alī Dīnār, fils du sultan Zakariyā, fils du sultan Muhammad alFaḍl, 1316 [?]/1898

B) Sur le côté intérieur de la lame.

Dans un cadre rectangulaire, une ligne en écriture cursive; exécutée à l'eau forte.

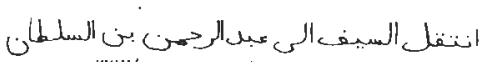

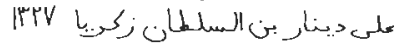

Le sabre a été transferé à 'Abd al-Raḥmān, fils du sultan 'Alī Dīnār, fils du sultan Zakariyā, 1327/1909

C) Sur la poignée.

I. Sur la surface d'une extrémité de la garde

Dans un cadre en forme de losange; trois lignes, au-dessous la date; écriture cursive; caractères gravés et remplis d'une pâte noire.

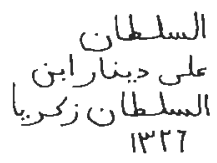


(1) Sultan

(2) 'Alì Dīnār, fills

(3) du sultan Zakariyā 1326/1908 (Fig. 19a)

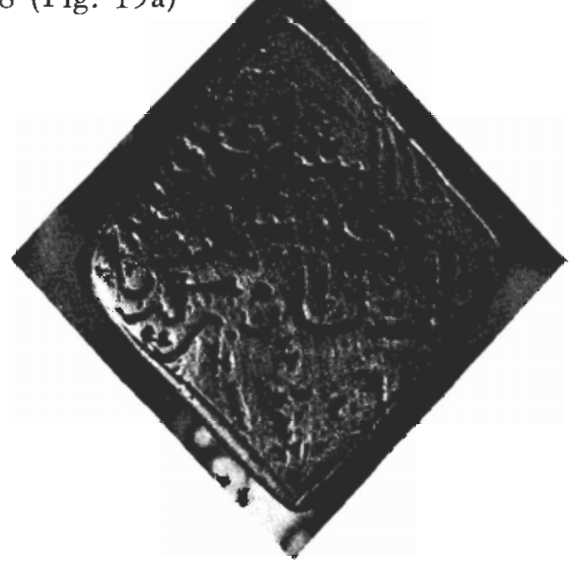

Fig. 19a

II. Sur la surface de l'autre extrémité de la garde

Dans un cadre en forme de losange; inscription ornementale; gravée et remplie d'une pâte noire.

Tughra de 'Alī Dīnār $(F i g .19 b)$.

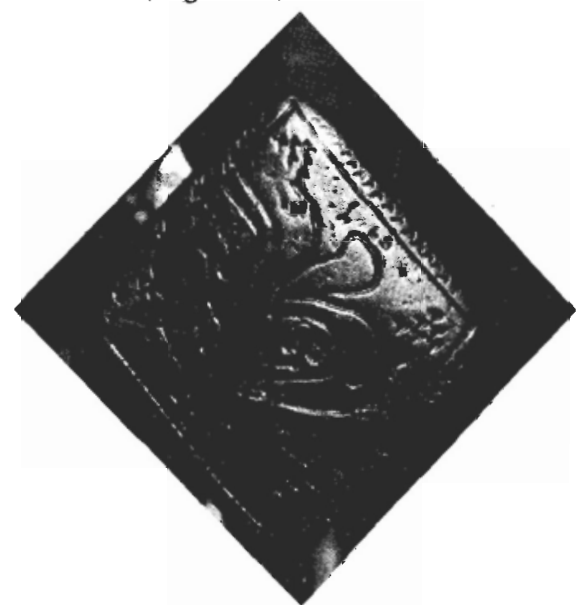

FIG. 19b

66 
D'après le registre de la Tour de Londres «belonged to Sultan Ali Dinar and dated 1887».

Le sultan 'Alĩ Dīnār est le sultan du Darfour, arrivé au pouvoir en $1302 / 1885^{19}$. L'inscription no. II enregistre le transfert du sabre à son fils en 1327/1909, tandis que sur l'une des extrémités de la garde de la poignée le nom du père est accompagné encore de la date 1326/1908.

\section{b) Poignards}

No. 33 Poignard à poignée en os

Iran, XVIII-XIXème siècle

No. de l'inv. 26/65 D

Sur le côté extérieur de la poignée, sur la pointe.

Une ligne en écriture cursive; caractères en relief.

$$
\text { sacole. }
$$

O ‘Alī, secours!

No. 34 Poignard

Iran, XIXème siècle

No. d'inv. 26/64 D

Sur la poignée en os sculpté.

Sur les deux côtés (A et B), une ligne en haut (1) et en bas (2), dans un cadre rectangulaire perlé; écriture cursive ( $\left.t a^{\prime} l i q\right)$, quelques points; sur un fond à décor floral très schématisé.

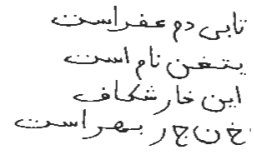

(1) $-A$

(1) $-B$

A - (1) Le brillant est le tranchant aigu

(2) Le nom est yatagian

B - (1) Celui qui fend une épine

(2) Est le ḩain ğa $\mathrm{r}$ (poignard) étonnant (Figs. 20a-d)

19 Cf. E. de Zambaur, Manuel de généalogie et de chronologie pour l'histoire de l'Islam, Hannover, 1927, p. 90. 


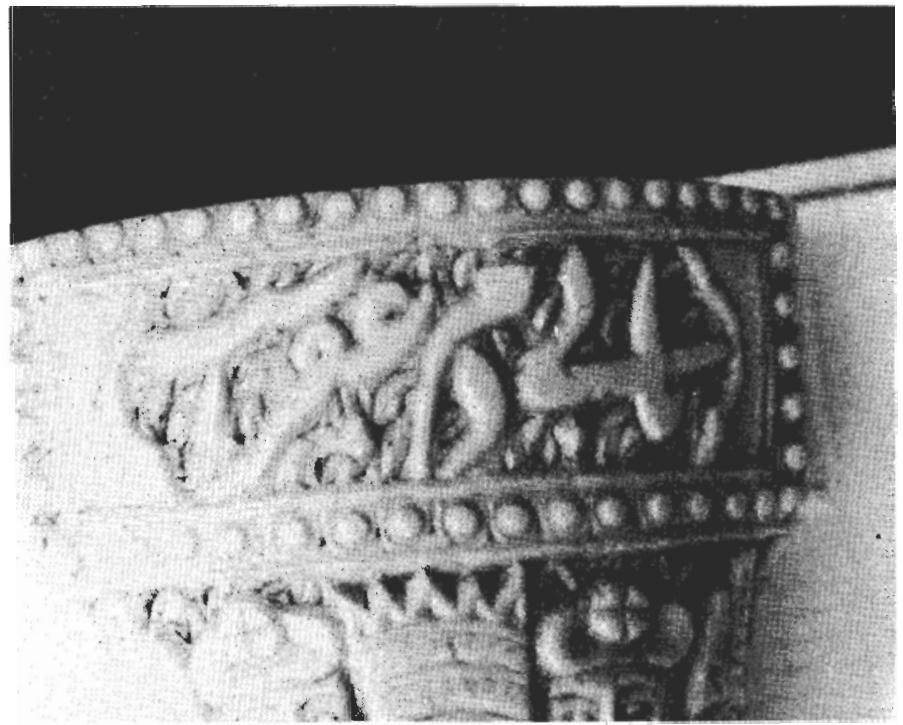

Fig. 20a

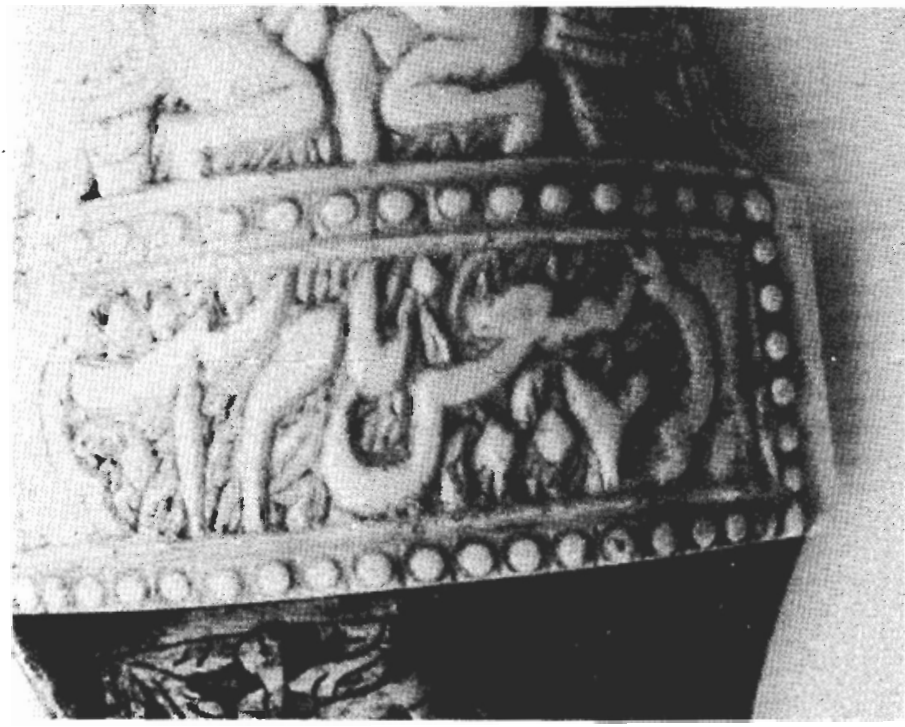

F1G. 20b 


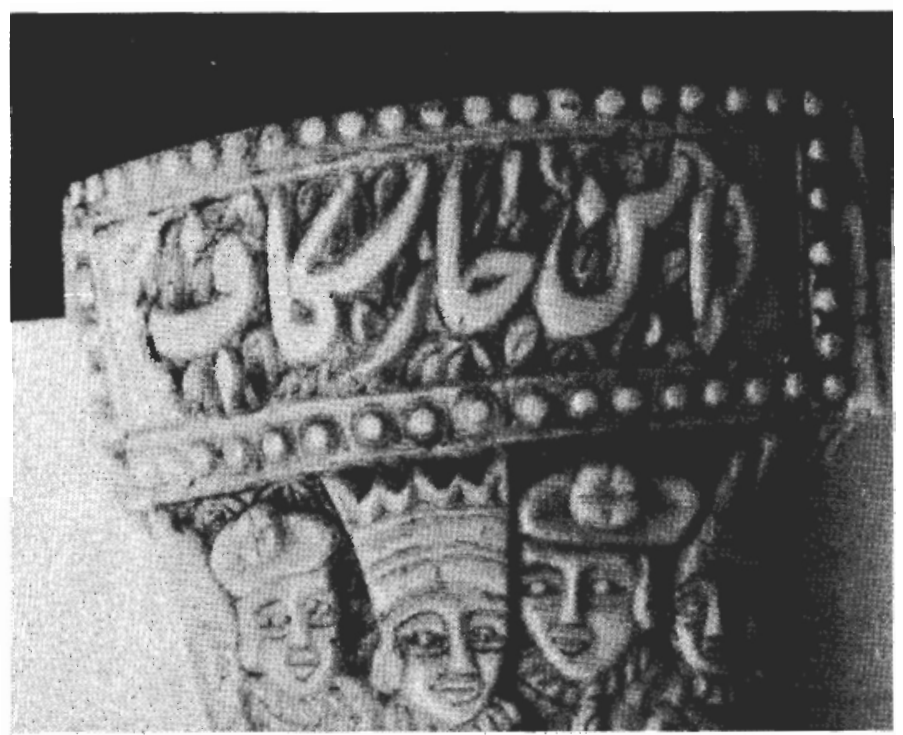

FIG. 20c

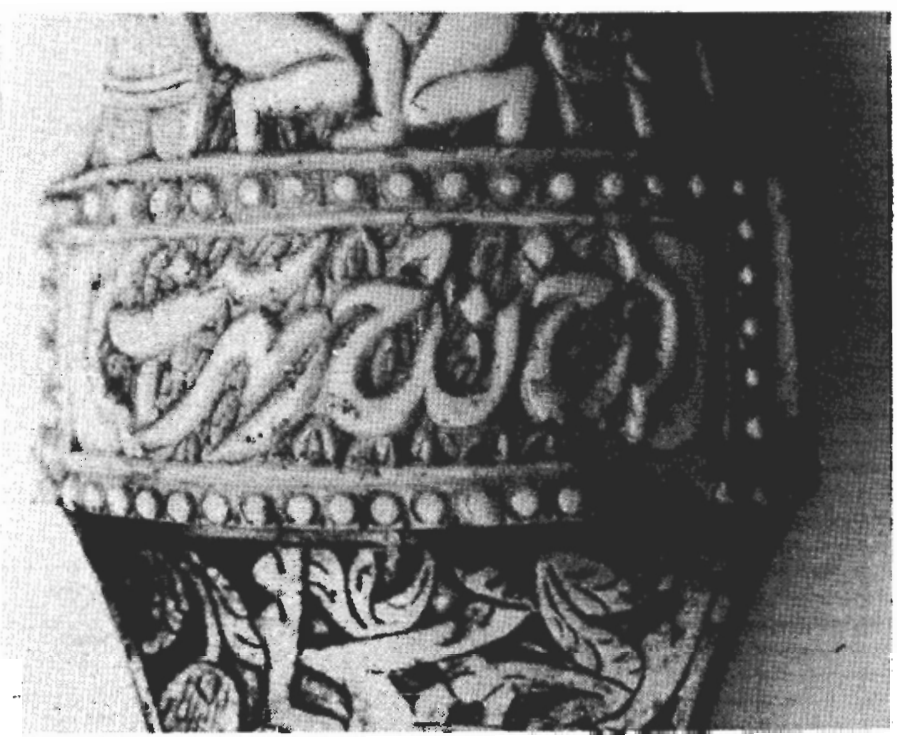

FIG. 20d 
Quatrain persan louant les qualités du poignard. Les caractères du mot hanğar (poignard) ne sont pas reliés, ce qui donne à ce mot une certaine puissance talismanique.

No. 35 Poignard à lame droite

Caucase, début du XXème siècle

No. d'inv, 26/55 D

I. Sur un côté de la lame

Un mot gravé en écriture cursive.

$$
\text { Zekerī (Zacharias) w; }
$$

II. Sur l'autre côté de la lame

Date gravée.

\section{$1325 / 1907$ Irro}

Nom d'un personnage qui pourrait être soit le fabriquant du poignard, soit son propriétaire.

$$
\text { c) Hacbe }
$$

No. 36 Hache en acier

Iran, fin du XVIIIème siècle

Prêté par le Victoria and Albert Museum

\section{Sur l'une des deux faces}

Sur la partie dépassant le manche après l'emmanchement, un cartouche (A); sur la hache elle-même, un grand (B) et un petit (C) cartouche. Écriture cursive; caractères damasquinés d'or.

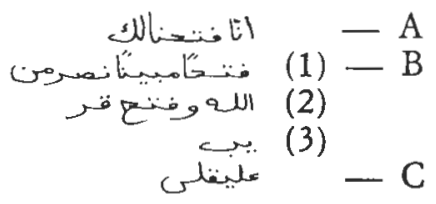


$A$ et $B-$ «En vérité, Nous t'avons octroyé un succès éclatant.» (Cor. XLVIII, 1) «Secours de Dieu et prochain succès!» (Cor. LXI, 13)

$\mathrm{C}-$ 'Alīqulī

\section{Sur l'autre des deux faces}

Sur la partie dépassant le manche après l'emmanchement, un cartouche (A); sur la hache elle-même, un grand cartouche (B). Écriture cursive; caractères damasquinés d'or.

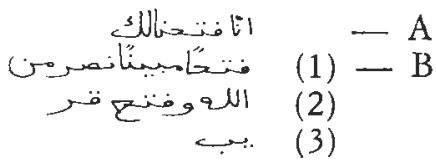

$A$ et $B-$ «En vérité, Nous t'avons octroyé un succès éclatant.» (Cor. XLVIII, 1) «Secours de Dieu et prochain succès!» (Cor. LXI, 13)

Vers coraniques se répétant sur les deux faces, avec le nom d'un personnage qui pourrait être le commanditaire de l'objet ou son fabricant.

d) $A r c$

No. 37 Arc

Turquie, 1838

No. d'inv. 26/37 B

I. Sur le côté intérieur

Une inscription sur chaque extrémité (A et B); écriture cursive; appliquée au princeau.

A - Année 1254/1838

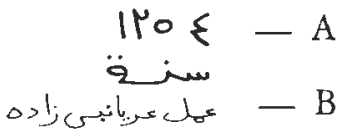

B - Oeuvre du fils de 'Uryānabī

II. Sur le côté extérieur

Sur l'une des deux extrémités, une courte inscription partiellement effacée et rendue illisible. 
Signature de l'artisan et.la date. D'après les fiches du musée son nom est lu «Uryani-zade».

\section{e) Fusils}

No. 38 Fusil

Maroc, fin du XVIIIème siècle

No. d'inv. 26/134 F

Sur la face supérieure du canon à profil hexagonal.

Bandeau correspondant à la largeur de la face, contenant une ligne en écriture cursive; le fond est constitué d'un décor floral très schématisé, dont certains éléments se confondent avec les caractères; damasquiné d'or. Le bandeau est interrompu par un élément décoratif rapporté en forme de fleur stylisée présentée à plat. Le début de l'inscription est effacé. L' intérieur du bandeau est divisé en quelques compartiments, peut-être au nombre de cinq (le nombre exact n'a pu être déterminé vu

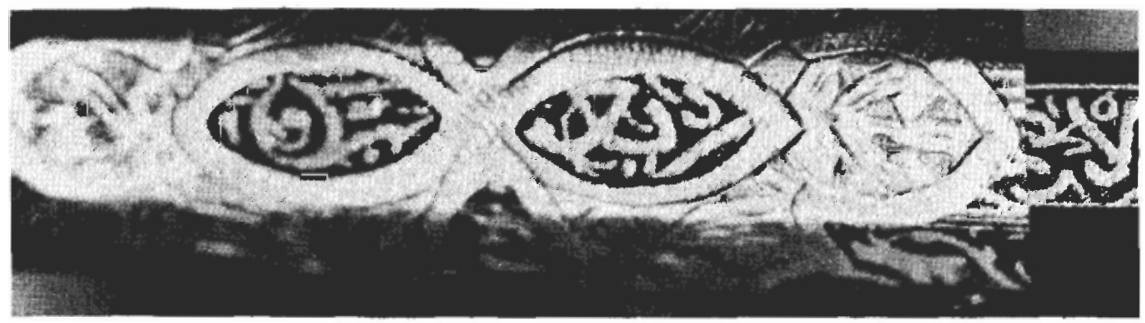

FIG. 21a

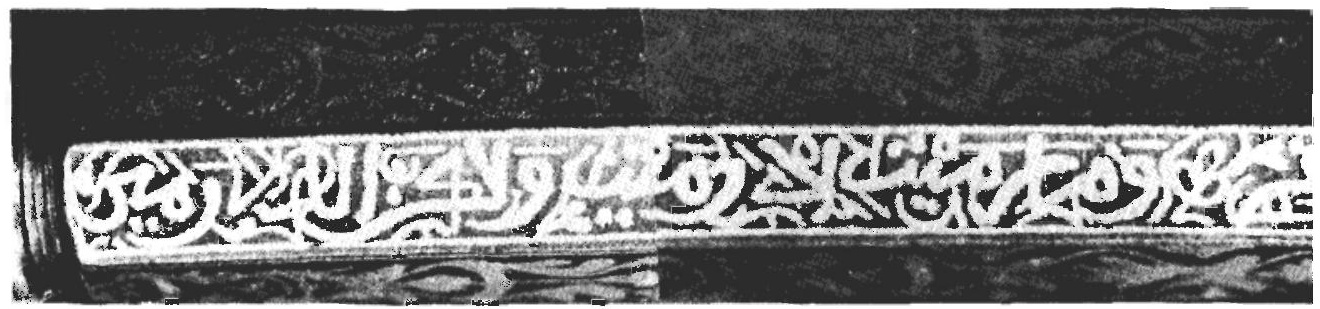

FIG. 21b 
l'effacement du début de l'inscription et son interruption par l'élément décoratif rapporté).

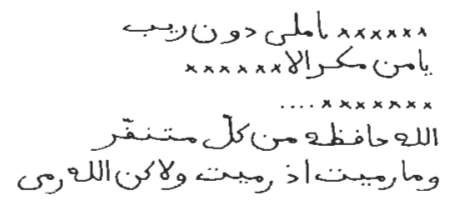

(1) $\operatorname{xxxxxx} \ldots$ sans aucun doute

(2) [«Seul le peuple des Perdants] est-il à l'abri de la machination [de Dieu?»] (Cor. VII, 97/99) (Fig. 21a)

(3) $\operatorname{xxxxxx} \ldots$

(4) Dieu est son gardien contre tout un chacun qui abhorre

(5) «Tu n'as point visé quand tu as visé. C'est Dieu qui a visé» (Cor. VIII, 17) ${ }^{20}$ (Fig. 21b)

D'après M. Reinaud, Monumens arabes, persans et turcs, du cabinet de $M$. le Duc de Blacas et d'autres cabinets, Paris, 1828, t. I, p. 213, note 2, "ces paroles se lisent encore sur les lances, les piques et les armes de trait des Musulmans.»
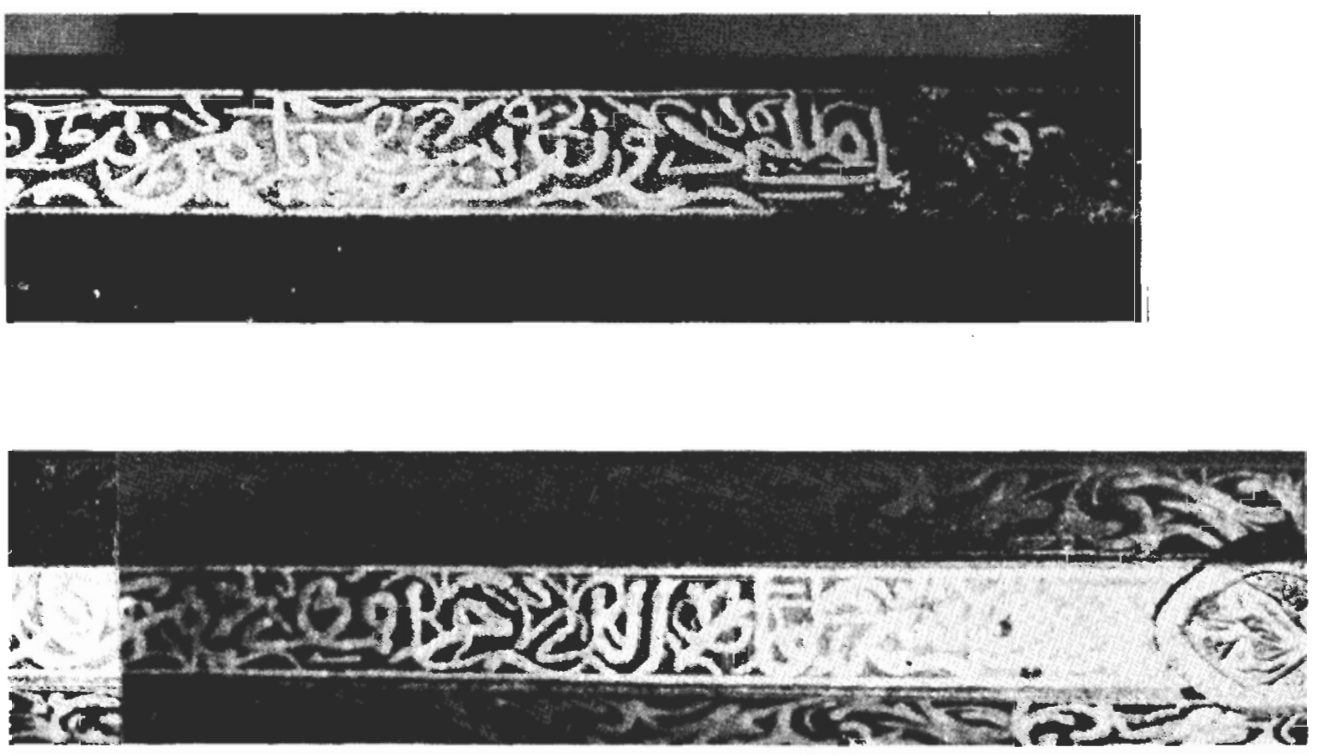
L'effacement de l'inscription ne permet pas de saisir entièrement son sens, mais les fragments lus nous montrent que l'inscription exprime la puissance de Dieu qui dirige tous nos actes.

No. 39 Canon d'un fusil de chasse

Inde, fin du XVIIIème siècle. D'après la fiche du musée, fabriqué à la Royal Manufactory de Mysore en 1794-95 et pris dans l'arsenal' de Tipu Sultan après la prise de Seringapatam en 1799

No. de l'inv. 26/46 F

I. Sur la face supérieure du canon à profil hexagonal

Quatre cartouches allongés aux extrémités polylobés, se suivant; une ligne dans chaque cartouche; écriture cursive ( $\left.t a^{\prime} l i q\right)$; caractères gravés, le creux est rempli d'une pâte noire. Un carré magique précède l'inscription.

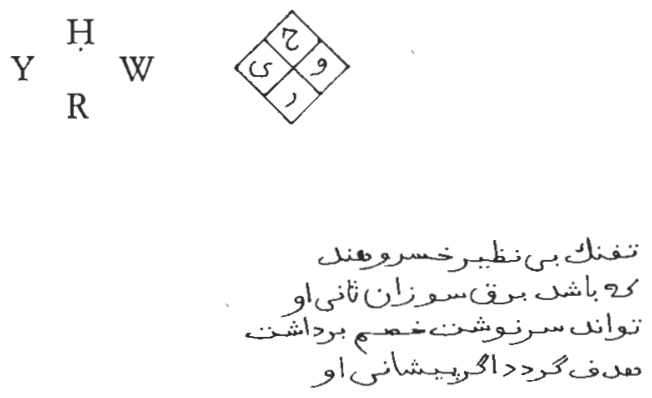

(1) Le fusil incomparable du grand roi de l'Inde

(2) Qui n'a d'égal que la foudre destructive

(3) Peut dédaigner le destin de l'ennemi

(4) Si son front devient sa cible (Figs. 22a-d)

II. Sur les deux faces contigües de la face supérieure, à sa gauche (A) et à sa droite (B). Deux (A) et trois (B) lignes en écriture cursive ( $t a^{\mathrm{s}}$ lìq); caractères gravés, le creux èst rempli d'une pâte noire

$$
\text { - A }
$$




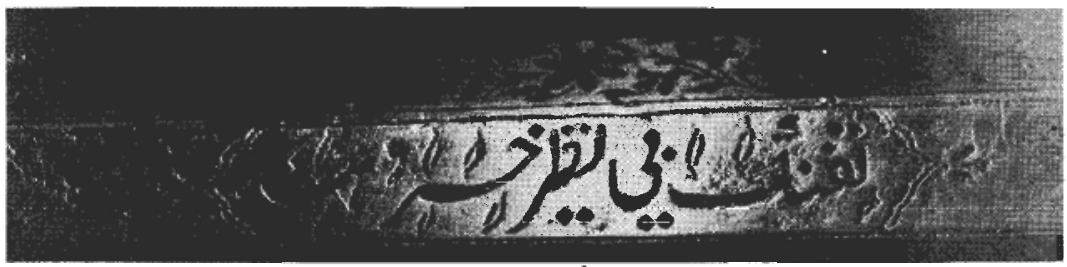

FIG. 22a

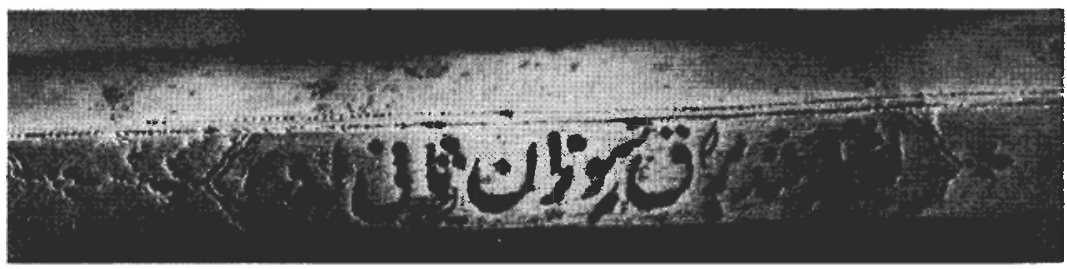

FIg. 22b

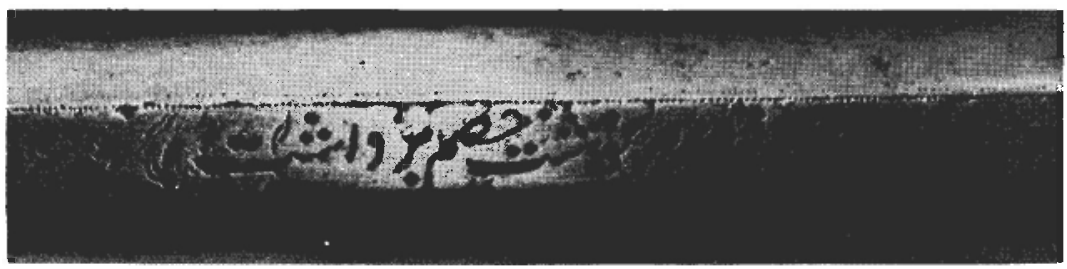

FIG. 22c

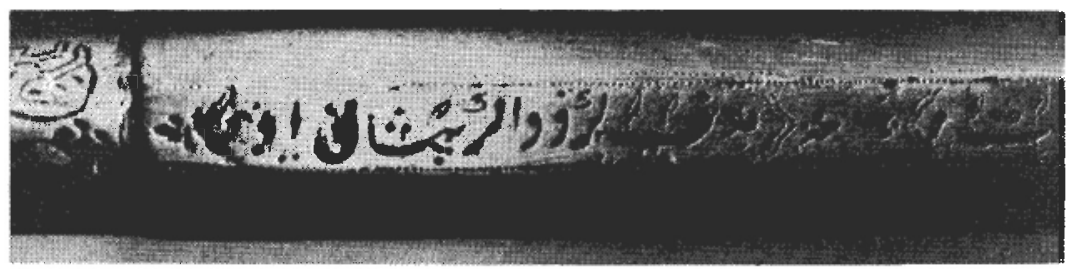

FIG. 22d 


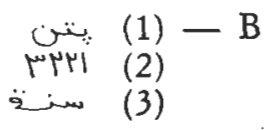

A - Asad Golāb (Fig. 23a)

$\mathrm{B}$ - L'année 1223/1795, «la Ville» ${ }^{21}$ (Fig. 23b)

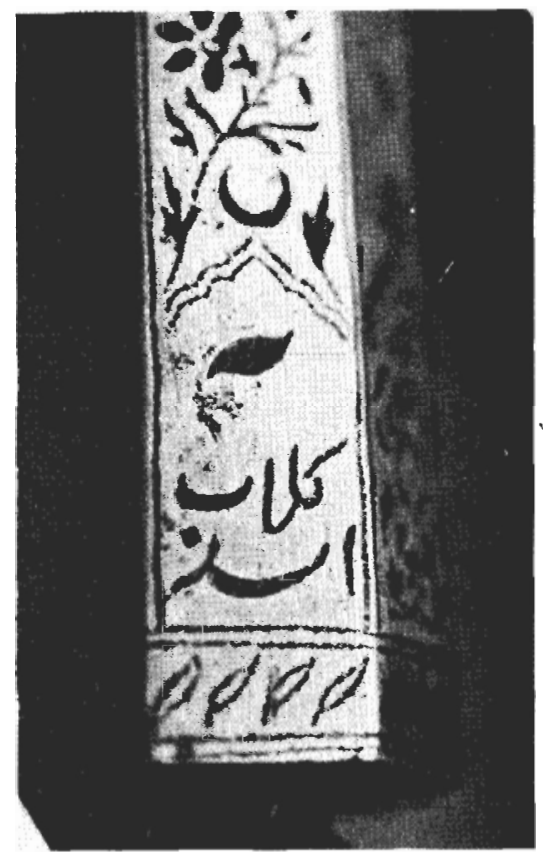

FIG. 23a

III. Plus loin sur le canon, sur le sommet de sa partie cylindrique

Deux cartouches en forme d'amande, disposés symétriquement autour d'un axe imaginaire passant au sommet du canon. Un mot dans

${ }^{21}$ Pour la date et pour le nom «la Ville» cf. ci-dessus, notes 16 et 17. 


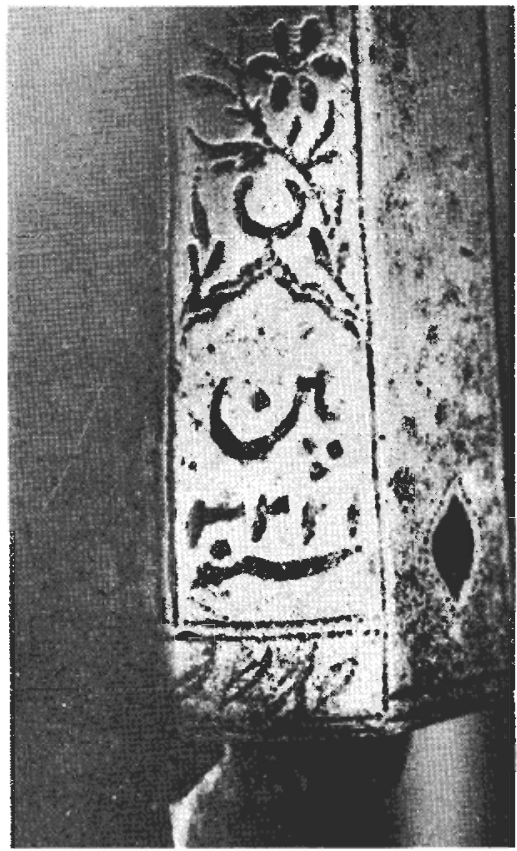

FIG. 23b

chaque cartouche, à droite $(\mathrm{A})$ et à gauche $(\mathrm{B})$; écriture cursive; caractères gravés, le creux est rempli d'une pâte noire.

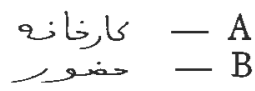
A - Arsenal
B - de la cour

IV. Plus loin sur la partie cylindrique du canon, au sommet

Dans un cartouche circulaire entouré de rayons de soleil; écriture décorative composée de deux moitiés symétriques autour d'un axe vertical imaginaire (en miroir); caractères gravés, le creux est rempli d'une pâte noire. 
Non déchiffré (Fig. 24).

L'inscription contient quatre vers persans décrivant la puissance du fusil. Le fusil faisait partie de l'arsenal de Tipu Sultan à Seringapatam

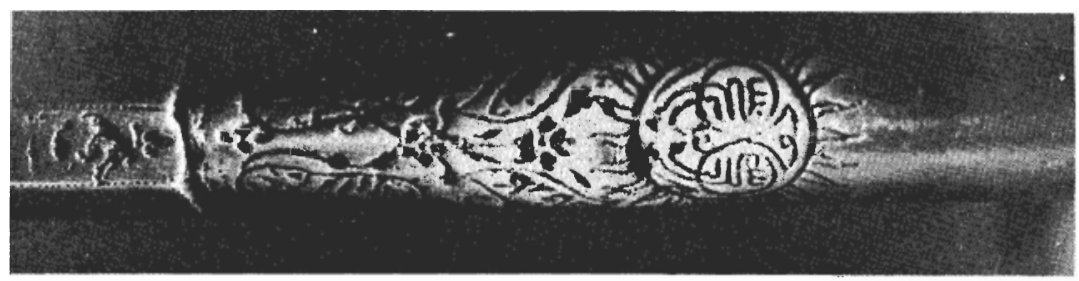

FIG. 24

(cf. le sabre no. 21) et le nom d'Asad Golāb est apparemment le nom du fabricant.

Les inscriptions arabes et persanes sur les armes musulmanes de la collection de la Tour de Londres, présentées ci-dessus, nous font entrevoir la variété des inscriptions sur les armes musulmanes en général. Certes, ces inscriptions ne sont qu'un échantillon fourni par une collection formée au hasard des acquisitions et non dans le but précis de constituer une collection systématique des armes musulmanes où l'on pourrait voir représentés des objets de tous les types, de toutes les régions et de toutes les périodes. Ainsi il nous est difficile, à partir de cette collection, de tirer des conclusions d'ordre général concernant les inscriptions sur les armes musulmanes. L'inventaire présenté ici se veut être une contribution à un corpus qui reste à établir et sa réalisation ne sera possible qu'à l'aide d'inventaires analogues récensant le plus grand nombre possible d'inscriptions sur les armes se trouvant dans les collections publiques ou privées du monde entier. 